\title{
Finding a Good Price in Opaque Over-the-Counter Markets*
}

\author{
Haoxiang Zhu \\ Graduate School of Business, Stanford University \\ This version: December 7, 2010 \\ First version: October 2009
}

\begin{abstract}
This paper offers a fully rational, dynamic model of opaque over-the-counter markets. An investor searches for an attractive price by visiting multiple dealers in any chosen sequence, including repeat contacts. The dealers do not observe negotiations elsewhere in the market, including the order of contacts. Under stated conditions, a repeat contact with a dealer reveals the investor's reduced outside options and worsens the price quote. When the fundamental value of an asset is uncertain, market opacity and uncertain contact order could exacerbate adverse selection and lead to inefficient market breakdown.
\end{abstract}

Keywords: over-the-counter market, transparency, adverse selection, market breakdown, bargaining, outside options, search

JEL Classification: G14, C78, D82, D83

*I am very grateful to Darrell Duffie for several discussions and many helpful comments. For conversations and helpful comments, I thank Anat Admati, Jules van Binsbergen, Simon Board, Jeremy Bulow, Peter DeMarzo, Songzi Du, Xavier Gabaix, Steve Grenadier, Denis Gromb, Yesol Huh, Dirk Jenter, Ron Kaniel, Arthur Korteweg, Charles Lee, Doron Levit, Ian Martin, Stefan Nagel, Paul Pfleiderer, Monika Piazzesi, Martin Schneider, Ken Singleton, Andy Skrzypacz, Eric So, Ilya Strebulaev, Dimitri Vayanos, and Jeff Zwiebel, as well as seminar participants at Stanford GSB. All errors are my own. Corresponding address: 518 Memorial Way, Graduate School of Business, Stanford University, CA 94305. Email: haoxiang.zhu@stanford.edu. Paper URL: http://papers.ssrn.com/sol3/papers.cfm?abstract_id=1500809. 


\section{Introduction}

Trading in many segments of financial markets is over-the-counter (OTC). Compared to exchanges, OTC markets are opaque. For example, in markets for corporate bonds, municipal bonds, mortgage-backed securities, asset-backed securities, and exotic derivatives, firm (executable) prices are usually not quoted publicly, and traders often search for attractive prices by contacting multiple counterparties in sequence. Once a quote is provided, the opportunity to accept it lapses quickly. In corporate bond markets, for example, "Telephone quotations indicate a firm price but are only good 'as long as the breath is warm,' which limits one's ability to obtain multiple quotations before committing to trade" (Bessembinder and Maxwell (2008)). Even when quotes are displayed on electronic systems, they are often indicative and can differ from actual transaction prices. ${ }^{1}$ Electronic trading, which makes it easier to obtain multiple quotes quickly, is also limited in the markets for many fixed-income securities and derivatives. ${ }^{2}$

In this paper, I develop a model of opaque OTC markets. A seller, say a distressed investor, wishes to sell an indivisible asset to one of $N>1$ buyers, say quote-providing dealer banks. There is no pre-trade transparency. The seller must visit the buyers one at a time. When visited, a buyer makes a quote for the asset. The seller may sell the asset to the currently contacted potential buyer, or may turn down the offer and contact another buyer. Because a buyer does not observe negotiations elsewhere in the market, he faces contact-order uncertainty - uncertainty regarding the order in which the competing buyers are visited by the seller. The seller may also make a repeat contact with a previously rejected buyer when a new buyer's quote is sufficiently unattractive.

I show that the likelihood of repeat contact creates strategic pricing behavior by quote providers. When the seller and buyers have independent private values for owning the asset beyond its commonly known fundamental value, a returning seller faces no adverse price movement due to fundamental news, but invites adverse inference about the price quotes available elsewhere in the market. For example, a seller may initially refuse an unattractive bid from one buyer, only to learn that other buyers' bids are even worse. In this case, the seller takes into account the likely inference of the original buyer if she

\footnotetext{
${ }^{1}$ For example, Froot (2008) finds large and persistent disparity between quoted prices on Reuters and actual transaction prices. For TRACE-ineligible securities, which include the majority of MBS and ABS, transaction-quote disparity is 200bp for the bottom third of trade under the quote and 100bp for the top third of trades over the quote. The disparity shrinks by only about a half ten days after the trade. For TRACE-eligible securities, the corresponding numbers go down to about $100 \mathrm{bp}, 50 \mathrm{bp}$, and 0.2 , which are still substantial.

${ }^{2}$ For example, SIFMA (2009) finds that electronic trading accounts for less than $20 \%$ of trading volume in Europe for credit, ABS, and sovereigns, among others. The fraction is $0 \%$ for credit default swaps (CDS). Barclay, Hendershott, and Kotz (2006) finds that the market share of electronic intermediation falls from $81 \%$ to $12 \%$ when U.S. Treasury securities go off-the-run.
} 
contacts him for a second time. Upon a second contact by the seller, the original buyer infers that the seller's outside options are sufficiently unattractive to warrant the repeat contact, despite the adverse inference. He revises his bid downward accordingly. The intuition that a repeat contact signals a reduced outside option, and results in a lower offer, is confirmed as the first main result of this paper.

As the second main result of this paper, I show that when the fundamental value of the asset is uncertain, the joint effect of contact-order uncertainty and the lack of pretrade transparency could lead to severe adverse selection and even market breakdown. To see the intuition, suppose that the seller observes the fundamental value of the asset, but that buyers observe only independent noisy signals. The seller randomly chooses the order of contact with the buyers. To avoid no-trade (Milgrom and Stokey (1982)), I also assume that buyers have higher private values for owning the asset than the seller.

I show that a buyer's expected fundamental value of the asset conditional on his own signal and on being contacted, E(V|signal, contact), is strictly lower than the expected fundamental value of the asset conditional only on his own signal, $E(V \mid$ signal $)$, provided $N \geq 2$. Intuitively, the fact that the asset is currently offered for sale means that nobody has bought it so far, which in turn suggests that other buyers may have received pessimistic signals of its fundamental value. Anticipating such adverse selection, a buyer may quote a low price for the asset, even when his own signal indicates that the fundamental value of the asset is high.

Moreover, a buyer's expected fundamental value of the asset is decreasing in the number $N$ of buyers in the market. For arbitrarily precise (but imperfect) signals, as $N \rightarrow \infty$, all buyers disregard their own signals and quote low prices, even if the true asset value is high and all signals are high. As a result, the market could break down. In transparent markets, large amounts of dispersed information would be aggregated through public price (Grossman (1976)), whereas in opaque market modeled here, the lack of price transparency prevents information aggregation and causes severe adverse selection. The market breakdown also suggests, perhaps surprisingly, that an opaque OTC market could in some cases benefit from fragmentation. That is, a limited number of available counterparties could alleviates adverse selection created by opacity.

This paper seems to be the first that captures the joint implications of uncertain contact order, fully strategic quotes, and market opacity. Although the model proposed is simple and is set in the context of security trading, the intuition provided by the equilibrium results seem applicable in other opaque decentralized markets, such as the markets for security lending, repo, bank loans, and venture capital, among others. 


\subsection{Relation to the literature}

The ability of quote providers to revise their quotes upon repeat contacts distinguishes this paper from the literature of sequential search with recall. For example, in the dealer-market models of Biais (1993), de Frutos and Manzano (2002), Yin (2005), and Green (2007), the quote providers commit to their original quotes when the quote seeker returns. In this paper, as in functioning OTC market for financial securities, a rejected quote lapses immediately. Repeat contacts are absent in models based on the "random matching" of an infinite number of buyers and sellers, as in Duffie, Gârleanu, and Pedersen (2005, 2007), Vayanos and Wang (2007), and Vayanos and Weill (2008), among others. In this paper, the number of traders is finite and repeat contacts have a material effect on the prices quoted.

Although search and bargaining have long been studied in the context of real estate markets, the model of this paper more closely resembles the reality of the OTC financial markets. First, rejected offers in real estate markets can often be recalled, as modeled by Quan and Quigley (1991) and Cheng, Lin, and Liu (2008), whereas rejected offers in markets for OTC financial securities lapse quickly. Second, buyers and sellers in real estate markets trade with each other directly, sometimes hiring brokers as agents to speed up the search process (Yinger (1981) and Yavas (1992)). In this paper, as in the markets for OTC financial securities, dealers trade as principals on their own accounts. Third, outside options in real estate markets depend much on the exogenous arrivals of new buyers or sellers, whereas outside options of the quote seeker in this paper are endogenous of unobserved contacts to a commonly known group of dealers.

This paper highlights the role of market opacity in exacerbating adverse selection in decentralized markets. Compared to classical microstructure models such as Glosten and Milgrom (1985) and Kyle (1985), adverse selection identified in this paper not only comes from payoff-relevant private information, but also arises endogenously from contact-order uncertainty and market opacity. Increasing the number of dealers in opaque markets does not help information aggregation, but rather magnifies adverse selection and causes potential market breakdown. This type of adverse selection is absent in the OTC-market model of Duffie, Malamud, and Manso (2010), in which traders are matched exogenously and can trade multiple times. In that setting, meeting a buyer does not imply that this buyer has failed to find sellers.

Finally, this paper sheds light on bargaining models with outside options. Relevant papers include Chatterjee and Lee (1998), Muthoo (1995), de Fraja and Muthoo (2000), Gantner (2008), and Fuchs and Skrzypazc (2008), among others. In those models, outside options are often exogenous. A buyer's quote improves if the seller delays trade 
and comes back to the same buyer, because the delay signals a high valuation of the seller. In contrast, this paper makes an opposite prediction: When outside options are endogenous, a repeat contact reveals the weak outside options of the seller, thus worsening the price quotes.

\section{Model}

There is one quote seeker and two quote providers. (I later consider the case of $N>2$ quote providers.) Without loss of generality, suppose that the quote seeker is a seller and the quote providers are buyers. The seller has one unit of an indivisible asset she wishes sell. The buyers are ex-ante identical, and indexed by $i \in\{1,2\}$. I refer to a generic buyer as "Buyer $i$," and the other buyer as "Buyer $-i$." The seller's valuation $S$ and the buyers' valuations, $B^{(1)}$ and $B^{(2)}$, are independent and privately held information. ${ }^{3}$ (I later introduce a common component of asset valuations.) There are three valuation types for all traders: low $(L)$, medium $(M)$, and high $(H)$. For any $\theta \in\{L, M, H\}$, a type- $\theta$ seller has the valuation $S_{\theta}$ with probability $p_{\theta}$, and a type- $\theta$ buyer has the valuation $B_{\theta}$ with probability $p_{\theta}$. Without loss of generality, I normalize the valuation of a type- $L$ seller to 0 , and that of a type- $H$ seller to 1 . I also assume that $B_{\theta}=R S_{\theta}$, where $R>1$ is a constant that can be interpreted as a measure of gain from trade. I further assume that $B_{M}<S_{H}$, that is, $R S_{M}<1$. These are relatively innocuous parameter assumptions. The probabilities $p=\left(p_{L}, p_{M}, p_{H}\right)$ are strictly positive. The probability distributions of the valuations are summarized in Table I.

Table I: Probability distribution of the seller's and the buyers' asset valuations.

\begin{tabular}{c|ccc}
\hline \hline Probability & $p_{L}$ & $p_{M}$ & $p_{H}$ \\
\hline Seller Value & $S_{L}=0$ & $S_{M} \in(0,1 / R)$ & $S_{H}=1$ \\
Buyer Value & $B_{L}=0$ & $B_{M}=R S_{M}$ & $B_{H}=R$ \\
\hline
\end{tabular}

The market is over-the-counter, in a manner now to be described. Trading can potentially occur at any time $t \in\{0,1,2, \ldots\}$. The buyers and seller are risk-neutral and have a common discounting factor of $\delta$ per period. Each player maximizes the expected discounted profits generated by trading. The buyers are always present in the market. The seller arrives at the market at a stopping time $\tau_{S}$. This arrival time is known to the seller, but is not observed by either buyer. (Later, I show that the seller

\footnotetext{
${ }^{3}$ Private valuations can be interpreted as stemming from inventory positions, hedging needs, margin requirements, leverage constraints, or benefits of control, all of which are likely to be private.
} 
does not want to disclose his arrival time to the buyers.) The probability distribution of the seller's arrival time is common knowledge and given by

$$
P\left(\tau_{S}=t\right)=(1-\rho) \rho^{t}, \quad t \in\{0,1,2, \ldots\}
$$

where $\rho \in(0,1)$ is a constant known to all players.

One period after her arrival time $\tau_{S}$, the seller contacts one of the two buyers, randomly chosen with equal probability and independently of $\tau_{S}$. Upon contact, the selected buyer makes a bid for the asset. The seller cannot counteroffer, but can accept or reject the bid. If she accepts the bid, then the transaction occurs at the bid price and the game ends. If she rejects the bid, then the seller can: (i) quit the market, ending the game, (ii) wait one period without taking any action, or, (iii) at the next period, contact either the same buyer or the other buyer. Thus no action is ruled out. Upon the next contact, the same negotiation is repeated, and so on. A buyer does not observe contacts between the seller and the other buyer.

Figure 1 shows two possible game paths. Along these paths, the seller switches buyers after each contact. As shown, the buyers do not observe the order of contacts.

Now, more formally, I fix a probability space $(\Omega, \mathcal{F}, P)$. For a buyer $i$, let $F_{t}^{i}$ be the $\sigma$-algebra generated by all random variables observable to buyer $i$ up to and including time $t$. These random variables include whether the seller has contacted buyer $i$ at time $t$, but do not include buyer $i$ 's bid at time $t$. Buyer $i$ 's valuation, $B^{(i)}$, is $F_{0}^{i}$-measurable (known to the buyer at time zero). The time at which the seller first contacts the buyer $i$, denoted $\tau_{i}$, is an $\left(F_{t}^{i}\right)$-stopping time.

Let $G_{t}$ be the $\sigma$-algebra generated by all random variables observable to the seller up to and including time $t$. These random variables include the relevant buyer's bid at time $t$ (if the seller contacts any buyer at time $t$ ). The seller's private value $S$ is $G_{0}$-measurable. The seller's arrival time $\tau_{S}$ is a $\left(G_{t}\right)$-stopping time.

A strategy of Buyer $i$ at time $t$ is a $F_{t}^{i}$-measurable bid, denoted $b_{t}^{i}$. A strategy of the seller is a $\left(G_{t}\right)$-adapted process $s$, having outcomes at any time in $\left\{A, R_{1}, R_{2}, Q, N\right\}$, corresponding to: accept the bid $(A)$, request a new bid from buyer $i$ in the next period $\left(R_{i}\right)$, quit the market $(Q)$, and no action in the next period $(N)$. At any time $t<\tau_{S}$, the strategy $s_{t}$ by definition takes the value $N$. For $t=\tau_{S}, s_{t}$ must have the outcome $R_{1}$ or $R_{2}$.

Let $T_{i}$ be the time at which a bid from Buyer $i$ is accepted. (If Buyer $i$ 's bid is never accepted, then $T_{i}=\infty$.) Given strategies $b^{1}, b^{2}$, and $s$, the time- $t$ continuation utilities 
Figure 1: Two possible paths of the multi-period game. The seller is denoted "S". The first and second buyers contacted by the seller are denoted "1st" and "2nd," respectively. Along these paths the seller switch buyers after each contact. The circles represent one possible sequence of contacts by the seller, and squares represents another. A dotted line linking one circle and one square reflects a buyer's uncertainty regarding the contact order.

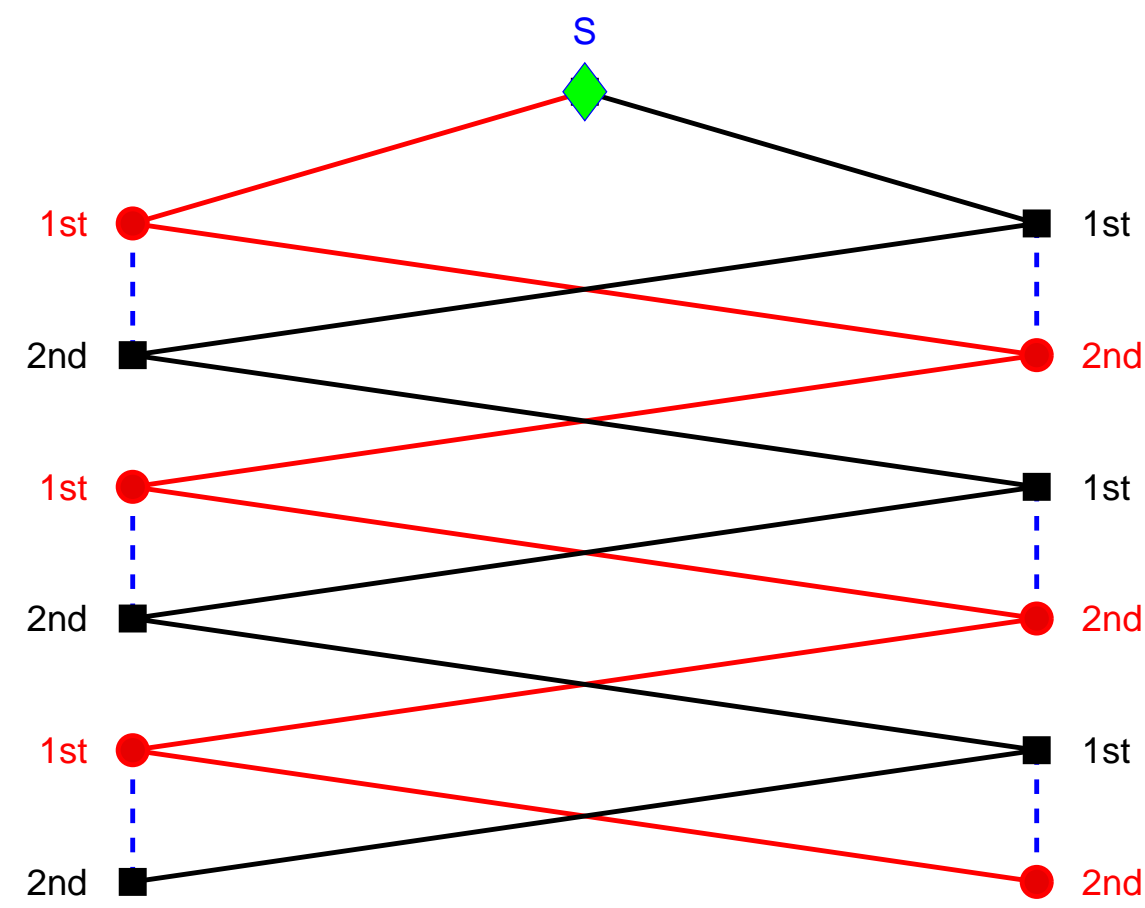

of the seller and buyer $i$ are

$$
\begin{aligned}
& U_{t}^{i}\left(b^{i}, b^{-i}, s\right)=\mathbb{E}\left[\delta^{T_{i}-t}\left(B^{(i)}-b_{T_{i}}^{i}\right) \mid F_{t}^{i}\right], \quad t \leq T_{i}, \\
& U_{t}^{S}\left(b^{1}, b^{2}, s\right)=\mathbb{E}\left[\delta^{T_{1}-t}\left(b_{T_{1}}^{1}-S\right) \mathbf{1}\left\{T_{1}<T_{2}\right\}+\delta^{T_{2}-t}\left(b_{T_{2}}^{2}-S\right) \mathbf{1}\left\{T_{2}<T_{1}\right\} \mid G_{t}\right], t \leq \min \left(T_{1}, T_{2}\right),
\end{aligned}
$$

respectively, where $b^{-i}$ denotes the other buyer's bidding strategy and $\mathbf{1}(\cdot)$ is the indicator function.

Definition 1 (Equilibrium). A perfect Bayesian equilibrium consists of buyers' strategies $b^{1}$ and $b^{2}$, and a seller's strategy s, such that, for any alternative strategies $\hat{b}^{1}, \hat{b}^{2}$, and $\hat{s}$,

$$
\begin{aligned}
& U_{t}^{i}\left(b^{i}, b^{-i}, s\right) \geq U_{t}^{i}\left(\hat{b}^{i}, b^{-i}, s\right), \quad t \leq T_{i}, \quad i \in\{1,2\} \\
& U_{t}^{S}\left(b^{1}, b^{2}, s\right) \geq U_{t}^{S}\left(b^{1}, b^{2}, \hat{s}\right), \quad t \leq \min \left(T_{1}, T_{2}\right) .
\end{aligned}
$$

In selecting an equilibrium, I focus on perfectly-revealing equilibria, in which the first 
bid of a buyer perfectly reveals his valuation. I also use the following tie-breaking rules for selecting equilibria,

1. Whenever indifferent between making a transaction or not, a player chooses to make a transaction.

2. Whenever an immediate gain from trade and the expected future gain from trade are equal, a player chooses to trade immediately.

3. If the probability of an eventual transaction is zero, then the seller leaves the market over the alternative of repeatedly contacting and rejecting buyers.

\section{Dynamic Equilibrium with Repeat Contact}

As the first main result of this paper, I will now characterize an equilibrium with repeat contact. Among the properties of this equilibrium, that most central to my objectives is the result that the price quoted by a type- $M$ buyer deteriorates upon a repeat contact. In equilibrium, a type- $M$ buyer bids a price that is moderately competitive in order to guarantee immediate trade with a type- $L$ seller, but that bid may not be high enough to guarantee immediate trade with a type- $M$ seller. (Thus a type- $M$ seller separates from a type- $L$ seller.) In the event that the seller makes a repeat contact, the type- $M$ buyer infers that the seller's outside option is sufficiently unattractive, and lowers his bid accordingly. In developing this equilibrium, I use the separation of a type- $M$ seller and a type- $L$ seller:

Definition 2 (Separating Equilibrium). An equilibrium is defined to be separating if, provided the first buyer contacted by the seller is of type $M$, the buyer's first quote is accepted by a type- $L$ seller, but is rejected by a type- $M$ seller.

Theorem 1 (Repeat-Contact Equilibrium). There is a nonempty, open set of parameters $\left(S_{M}, R, \delta, p, \rho\right)$ for which there exists a symmetric, fully-revealing perfect Bayesian equilibrium with repeated contact, such that, for $t \geq 2$,

1. A buyer of type $\theta$ bids $b_{\theta, k}$ upon the $k^{\text {th }}$ contact, where $b_{\theta, k}$ is defined by:

\begin{tabular}{c|ccc} 
bid $b_{\theta, k}$ & $\theta=L$ & $\theta=M$ & $\theta=H$ \\
\hline$k=1$ & 0 & $b_{M}$ & 1 \\
$k=2$ & off-eqm & $S_{M}$ & off-eqm
\end{tabular}

where "off-eqm" denotes off-equilibrium paths and where

$$
b_{M}=\frac{\delta^{2} p_{L}}{1-\delta p_{M}} S_{M}+\frac{\delta p_{H}}{1-\delta p_{M}} .
$$


A type- $M$ buyer's bid decreases upon repeat contact. That is, $b_{M}>S_{M}$.

2. The seller switches buyers or exits the market after each contact. A seller of type $\theta$ accepts a bid that is no lower than $A_{\theta}$, which depends on the history of contacts and is given by:

\begin{tabular}{c|ccc} 
Acceptable price $A_{\theta}$ & $\theta=L$ & $\theta=M$ & $\theta=H$ \\
\hline $1^{\text {st }}$ buyer's $1^{\text {st }}$ bid & $b_{M}$ & 1 & 1 \\
$2^{\text {nd }}$ buyer's $1^{\text {st }}$ bid & 0 & $b_{M}$ & 1 \\
$1^{\text {st }}$ buyer's $2^{\text {nd }}$ bid & off-eqm & $S_{M}$ & off-eqm
\end{tabular}

3. Equilibrium beliefs.

(i) The seller infers a buyer's type from his first bid: $A$ bid of $b_{\theta, 1}$ is from a type- $\theta$ buyer, where $b_{\theta, 1}$ is given by Part 1 of the theorem.

(ii) A type-M buyer infers that the seller is of type $M$ once she has rejects a bid of $b_{M}$ and then returned.

(iii) Upon the first contact by the seller, a buyer assigns probability $\alpha$ that he is the first buyer contacted and probability $(1-\alpha)$ that he is the second, where

$$
\alpha=\frac{\rho}{\rho+p_{L}+p_{M}\left(p_{M}+p_{H}\right)} .
$$

Upon the second contact by the seller, a buyer assigns probability 1 that he is the first buyer contacted.

4. Off-equilibrium beliefs. Suppose that a buyer's first bid is $b \neq b_{M}$. If $b \in\left(0, B_{M}\right)$, then the seller infers that the buyer is of type $M$. If $b \in\left(B_{M}, 1\right)$, then the seller's belief regarding the buyer's type is not updated.

Moreover, when a separating equilibrium characterized by 1-4 exists, it is unique.

Proof. See Appendix A.

Key to the repeat-contact equilibrium of Theorem 1 is a the strategic exploitation by a type- $M$ buyer of a type- $M$ seller's reduced outside option. In the presence of contactorder uncertainty, a type- $M$ buyer chooses to guarantee trades with a type- $L$ seller, but only quotes opportunistically with a type- $M$ seller. A type- $M$ buyer is willing to forgo an immediate trade with a type- $M$ seller, given the prospect of paying a lower price later, if the seller's outside option turns out to be sufficiently unattractive. Despite the threat of such adverse inference, a type- $M$ seller is nevertheless willing to forgo immediate trade with the first buyer, because her outside option is better, in expectation. 
The repeat-contact equilibrium has three paths on which transaction occurs, as illustrated in Figures 2, 3, and 4. On the first equilibrium path (Figure 2), the seller sells the asset upon the first contact with the first buyer. On the second equilibrium path (Figure 3), the seller sells the asset upon the first contact with the second buyer. On both paths, a type- $M$ buyer assigns probability $\alpha$ that he is the first buyer to be contacted. He cannot distinguish between the two equilibrium paths, and bids the same price $b_{M}$ on both. Seller types are not perfectly revealed even after the transaction takes place.

In contrast, when the seller makes a repeat contact with a buyer, she reveals her private valuation and outside options. On the third equilibrium path (Figure 4), the seller sells the asset upon the second contact with the first buyer. This happens, for instance, when the seller is of type $M$, the first buyer is of type $M$, and the second buyer is of type $L$. In fact, this is the only type profile that generates an equilibrium path with a repeat contact. Upon a repeat contact, the first buyer learns that the valuation of the seller is $S_{M}$, and that the valuation of the other buyer is 0 . He also infers the entire payoff-relevant history of the game. The buyer's new bid, $S_{M}$, is lower than his original bid of $b_{M}$. The seller, now in a worse bargaining position, accepts this lower price.

In this equilibrium, a repeat contact leads to a worse price. In classical bargaining models, outside options are exogenous, so a delay and a repeat contact signal a "strong" valuation, which in turn improves the price for the quote seeker. ${ }^{4}$ Here, a repeat contact simultaneously signals both a strong valuation and a weak outside option, but the effects of outside options on the prices are binding. Thus a repeat contact lowers the price offered.

Because repeat contacts reveal valuable information regarding outside options, a financial institution may benefit by keeping a complete history of its interactions with clients. Indeed, many broker-dealers organize their traders by specialization, whereby all transactions of a particular security are handled by one trader. This specialization reduces the opportunity for customers to avoid repeated contacts by contacting a different person in the same firm.

The results here also predict positive correlations between the quotes of different counterparties, even when these counterparties have independent valuations and have no means of direct communication. A sufficiently unattractive quote from a new counterparty is likely to be followed by another unattractive quote from the original counterparty, due to the inference drawn from a repeat contact. In effect, traders on one

\footnotetext{
${ }^{4}$ See, for example, Ausubel, Cramton, and Deneckere (2002) for related papers based on this intuition.
} 
Figure 2: Equilibrium path 1. The seller sells the asset upon the first contact with the first buyer (left panel). The buyer is uncertain of the contact order (right panel).
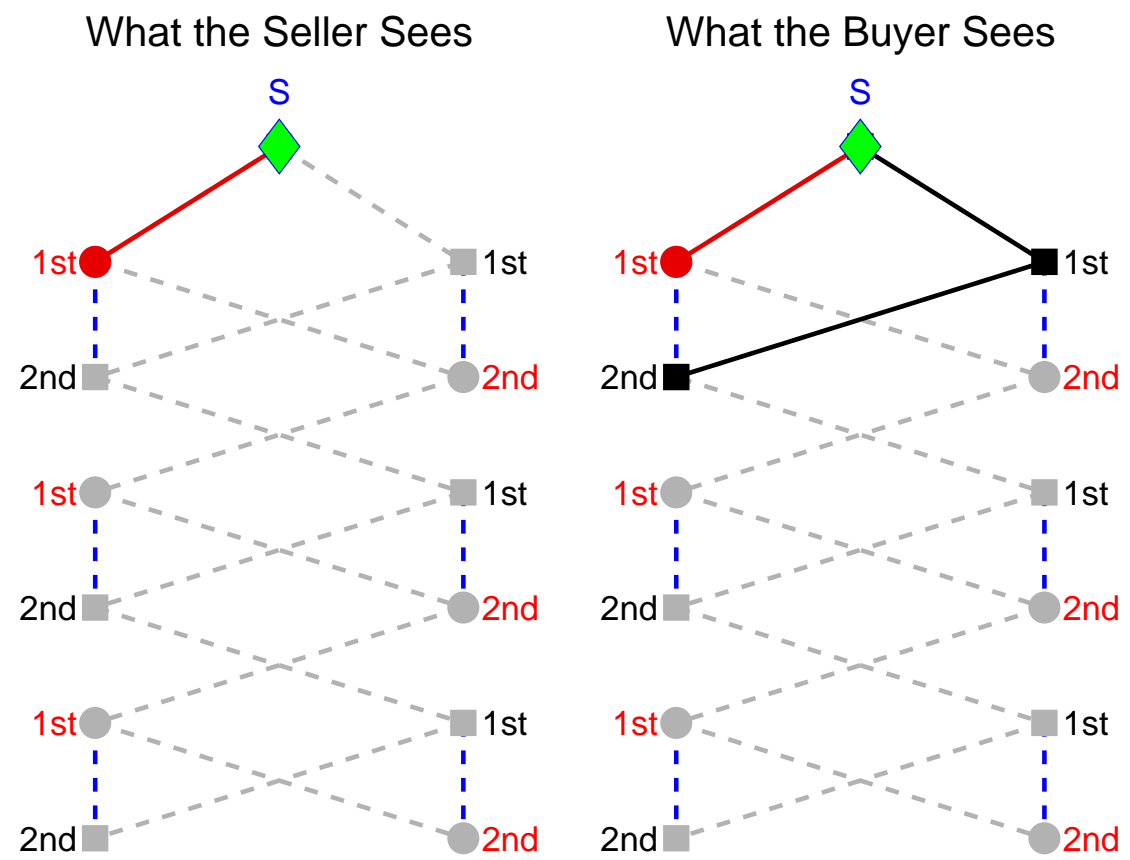

side of the market learn something about each other's valuations by interacting with the other side of the market. This learning generates positive correlation of the prices offered across the markets.

The choice to focus on the case of $b_{M}>S_{M}$ is motivated by the robustness of equilibrium behavior to a small delay cost. It is easy to see that, from (1), as $\delta \rightarrow 1$,

$$
b_{M} \rightarrow \frac{p_{L} S_{M}+p_{H}}{p_{L}+p_{H}}>S_{M}
$$

Finally, the repeat-contact equilibrium has the efficiency property that if the gain from trade is strictly positive, then trade occurs with probability 1. As illustrated in Figures 2, 3, and 4, delay may occur, but never lasts more than three periods. The repeat-contact equilibrium is, however, associated with misallocation costs and delay. When the first buyer is of type $M$ and the second buyer is of type $H$, a type- $L$ seller trades with the first buyer upon the first contact, implying an misallocation cost of $B_{H}-B_{M}$. When the first buyer is of type $M$ and the second buyer is of type $L$, a type- $M$ seller rejects the first buyer's bid but returns two periods later, implying an delay cost of $\left(1-\delta^{2}\right)\left(B_{M}-S_{M}\right)$. Both sources of inefficiency are direct consequences of market opacity that I further explore in later sections. 
Figure 3: Equilibrium path 2. The seller sells the asset upon the first contact with the second buyer (left panel). The buyer is uncertain of the contact order (right panel).
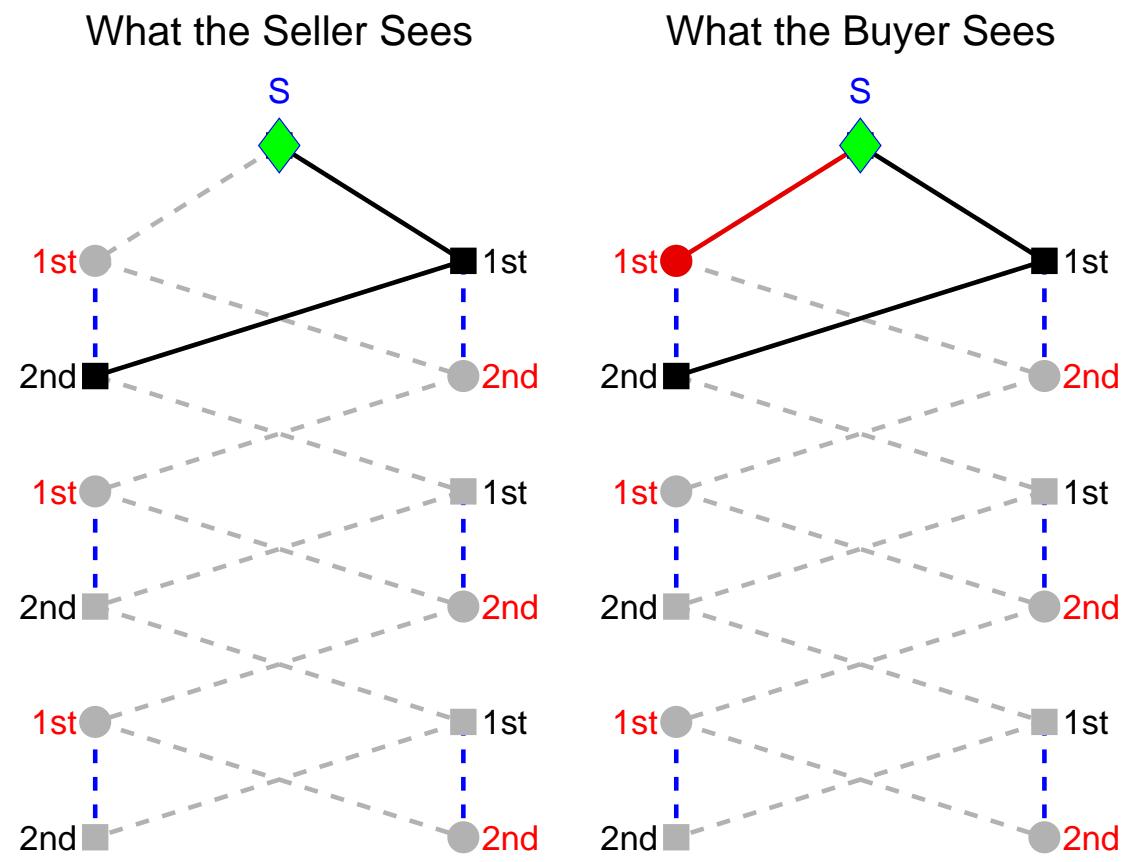

Figure 4: Equilibrium path 3. The seller sells the asset upon the second contact with the first buyer (left panel). The buyer infers the contact order (right panel).
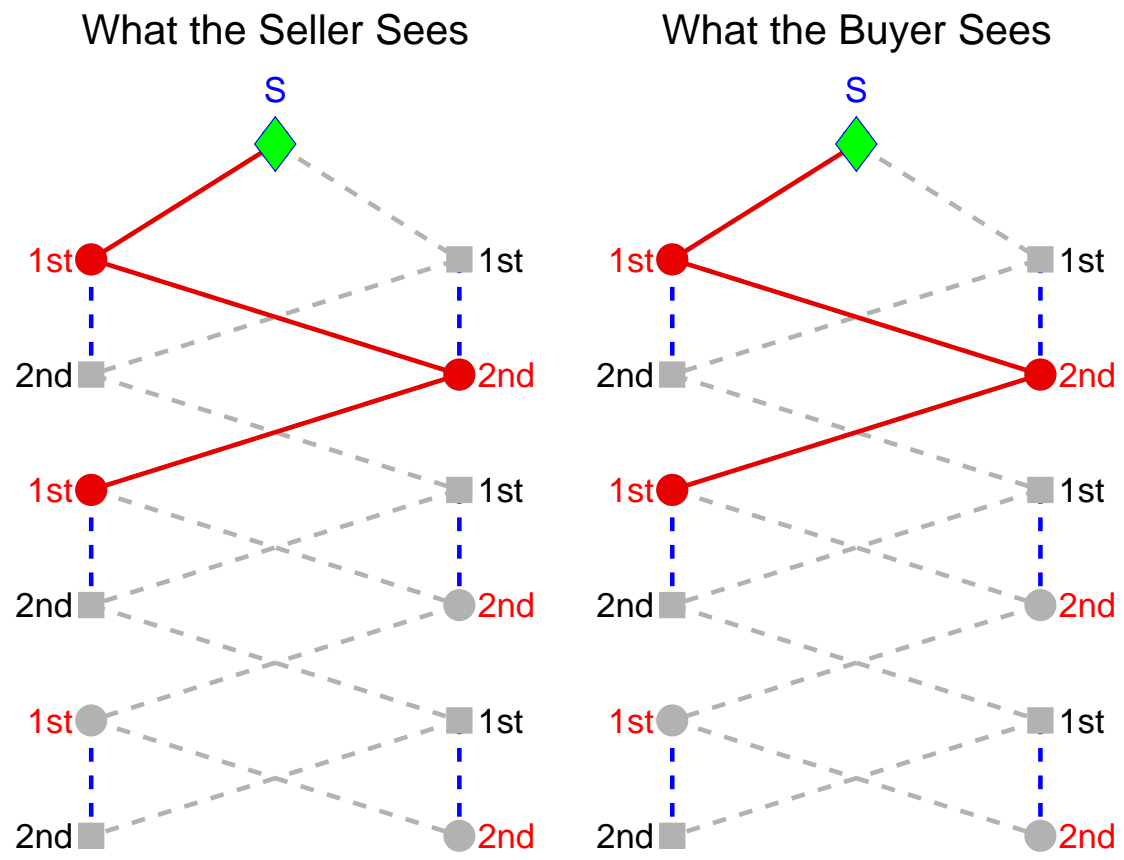


\section{Extensions}

In this section, I consider two extensions of the model studied in Sections 2 and 3. The first extension characterizes an equilibrium in which the first buyer knows the contact order. The second allows $N>2$ buyers in the market.

\subsection{Equilibrium with known contact order}

So far, I have presented a repeat-contact equilibrium in which buyers have incomplete information of the contact order. I now consider what happens if one buyer knows that he is the first buyer contacted, such as when the contact time is $t=1$ (an early seller, whose arrival time $\tau_{S}$ is 0 ). The knowledge of being the first gives a buyer a "first-mover" incentive to bid more aggressively, in order to secure a transaction with both the type- $L$ and type- $M$ sellers.

Proposition 1 (First-Mover Equilibrium). Suppose the information structure of the model allows the first buyer contacted to know that he is the first, but the second buyer contacted does not know that he is the second. Then there is an nonempty, open set of parameters $\left(S_{M}, R, \delta, p, \rho\right)$ for which there exists a perfect Bayesian equilibrium, such that:

1. The second buyer's strategy and belief are identical to those of Theorem 1.

2. The type- $\theta$ first buyer's bids are given by:

\begin{tabular}{c|ccc} 
first buyer's bid & $\theta=L$ & $\theta=M$ & $\theta=H$ \\
\hline on $1^{\text {st }}$ contact & 0 & $\bar{b}_{M}$ & 1 \\
on $2^{\text {nd }}$ contact & off-eqm & $S_{M}$ & off-eqm
\end{tabular}

where $\bar{b}_{M}$ equals the outside option of a type-M seller, and is given by

$$
\bar{b}_{M}=\delta\left(p_{M}\left(b_{M}-S_{M}\right)+p_{H}\left(1-S_{M}\right)\right)+S_{M}
$$

Moreover, $\bar{b}_{M}$ is strictly higher than $b_{M}$, defined by (1).

Appendix B calculates the incentive conditions for the existence of the first-mover equilibrium.

Figure 5 illustrates the $\left(S_{M}, R\right)$-pairs that admit the repeat-contact equilibrium or the first-mover equilibrium, for parameters $\delta=0.8, p_{L}=p_{M}=p_{H}=1 / 3$, and $\rho=0.99$. We observe that for some $\left(S_{M}, R\right)$, both of these equilibria exist. For any such parameters, a type- $M$ buyer is unwilling to bid competitively if the contact order is uncertain, but 
Figure 5: The area covered by circles admits the repeat-contact equilibrium of Theorem 1 . The area covered by crosses admits the first-mover equilibrium, for the parameters $\delta=0.8, p_{L}=p_{M}=$ $p_{H}=1 / 3$, and $\rho=0.99$.

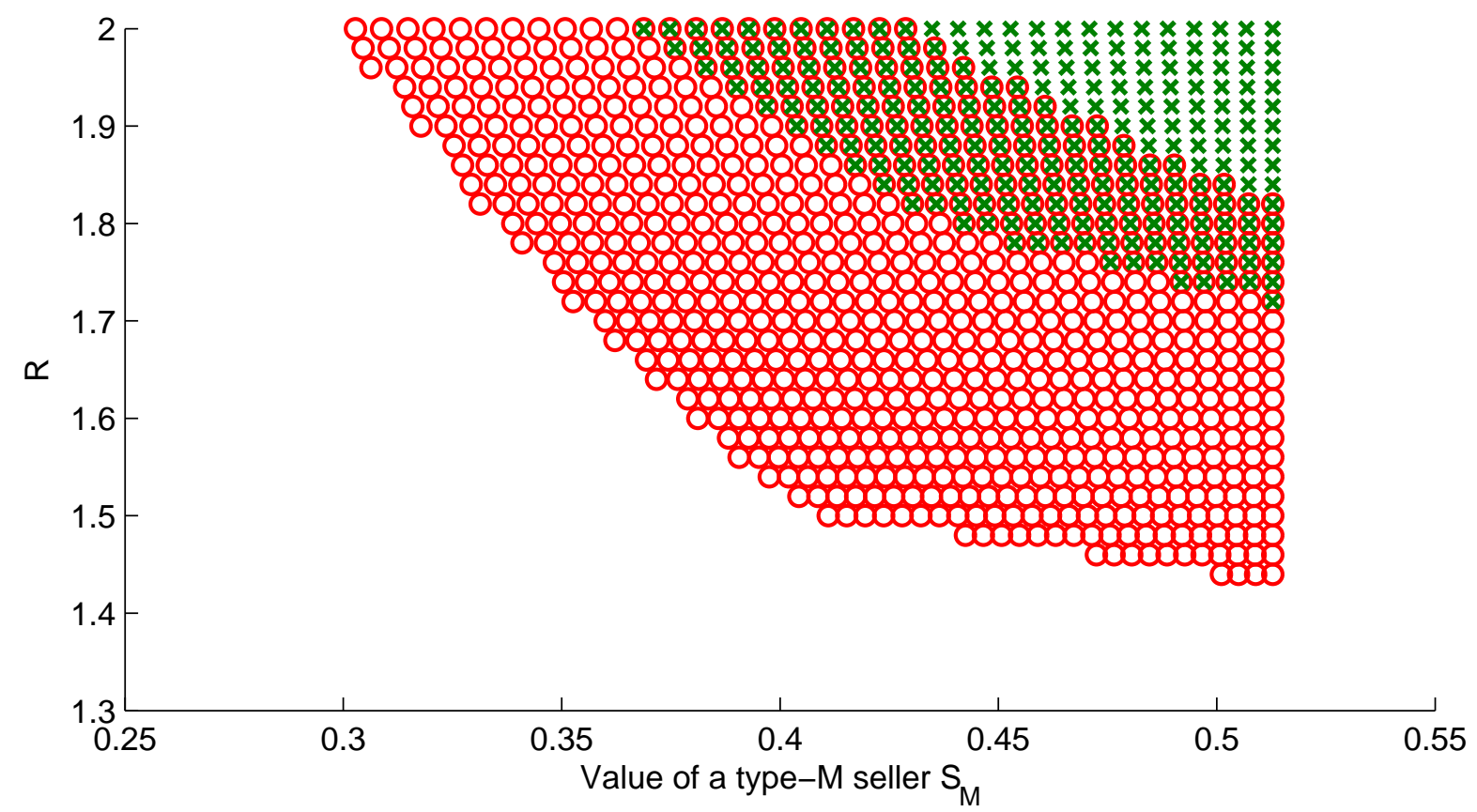

is willing to do so when he knows that he is the first buyer. As a result, an early seller (with $\tau_{S}=0$ ) gets a better price.

When both buyers know the order of contact, however, the seller is strictly worse off. To see this, suppose that the first buyer is Buyer 1 and the second buyer is Buyer 2. Also suppose that Buyer 2 is of type $M$. Once contacted, Buyer 2 knows that Buyer 1 is not of type $H$, and quotes a price of at most $S_{M}$, which is strictly lower than $b_{M}$. Anticipating Buyer 2's monopoly position, a type- $L$ seller's expected surplus from visiting him is reduced from $\delta\left(p_{L} S_{M}+p_{M} b_{M}+p_{H} 1\right)$ (as in the repeat-contact equilibrium) to at most $\delta\left(p_{L} S_{M}+p_{M} S_{M}+p_{H} 1\right)$. The corresponding type- $M$ seller's outside option also declines, from $\delta\left(p_{M}\left(b_{M}-S_{M}\right)+p_{H}\left(1-S_{M}\right)\right)$ to at most $\delta p_{H}\left(1-S_{M}\right)$. Lower outside options thus imply lower offers from Buyer 1. Quote seekers, therefore, benefit from choosing counterparties at random and hiding the order of their contacts. ${ }^{5}$

\footnotetext{
${ }^{5}$ Obviously, if the seller tries to get a better price by only disclosing contact order to the first buyer, then in equilibrium the second buyer knows that he is the second. I assume that the seller cannot tell both sellers that they are the first.
} 


\subsection{A market with $N$ buyers}

I now relax the two-buyer assumption and allow $N>2$ buyers. The other elements of the model are unchanged. As in the repeat-contact equilibrium of Theorem 1, I conjecture a symmetric, separating equilibrium with the properties that, for $t \geq N$ :

1. A type- $\theta$ buyer bids $b_{\theta, k}^{N}$ upon the $k^{\text {th }}$ contact by the seller, defined by:

\begin{tabular}{c|ccc} 
bid $b_{\theta, k}^{N}$ & $\theta=L$ & $\theta=M$ & $\theta=H$ \\
\hline$k=1$ & 0 & $b_{M, N}$ & 1 \\
$k=2$ & off-eqm & $S_{M}$ & off-eqm
\end{tabular}

where $S_{M}<b_{M, N}<1$.

2. A type- $\theta$ seller accepts a bid of $b_{M, N}$ if and only if she has $J_{\theta}$ or fewer buyers yet to visit, for some integer $J_{\theta} \leq N-1$, and for $\theta \in\{L, M\}$.

In this conjectured equilibrium, a bid decreases upon a repeat contact from $b_{M, N}$ to $S_{M}$. For now, I assume that such an equilibrium exists, and later discuss the conditions under which it may. The simple model studied in Sections 2 and 3 treats the special case of $N=2, J_{L}=1$, and $J_{M}=0$.

In this conjectured equilibrium, a seller contacts all $N$ buyers one by one. When there are many buyers yet to contact, a seller has a relatively good chance to meet a high-value buyer, and thus has a high continuation value for searching. The seller rejects a bid of $b_{M, N}$, despite the positive associated gain from trade. However, once the seller searches through many buyers and has failed to find a high bid, the probability of finding at least one high-value buyer declines. It also becomes increasingly likely that the seller must return to a previously rejected buyer and suffer a worse price. As a result, when there are relatively few buyers left, a seller accepts a price of $b_{M, N}$ as soon as it is quoted. Moreover, a seller with a lower value is more eager to sell than a seller with higher value. Therefore, a type- $L$ seller begins to accept a price of $b_{M, N}$ sooner than a type- $M$ seller. That is, $J_{L} \geq J_{M}$.

Formally, we let $W_{L}(n)$ be a type- $L$ seller's outside-option continuation value when there are $n$ buyers yet to visit, conditional on the seller having met a type- $M$ buyer, and let $W_{L}^{0}(n)$ be the corresponding continuation value conditional on the seller having not met a type- $M$ buyer. The Bellman principle implies that

$$
\begin{aligned}
& W_{L}(n)=\delta\left(p_{H}+\left(p_{M}+p_{L}\right) W_{L}(n-1)\right), \quad n \in\left\{J_{L}+1, J_{L}+2, \ldots, N-1\right\}, \\
& W_{L}(n)=\delta\left(p_{H}+p_{M} b_{M, N}+p_{L} W_{L}(n-1)\right), \quad n \in\left\{1,2, \ldots, J_{L}\right\}, \\
& W_{L}^{0}(n)=\delta\left(p_{H}+p_{M} W_{L}(n-1)+p_{L} W_{L}^{0}(n-1)\right), \quad n \in\{1,2, \ldots, N\},
\end{aligned}
$$


Figure 6: The reservation values of type- $L$ and type- $M$ buyers. Parameters: $N=6, \delta=0.8$, $p_{L}=p_{M}=p_{H}=1 / 3, J_{L}=2$, and $S_{M}=0.4$. The horizontal axis shows the number of buyers yet to be contacted, $n$. The triangles show the continuation value of a type- $L$ seller, $W_{L}(n)$, conditional on the seller having met a type- $M$ buyer. The diamonds show the continuation value of a type- $M$ seller, $W_{M}(n)$. The solid horizontal line is the equilibrium bid $b_{M, N}$ of a type- $M$ buyer. The dashed horizontal line is the surplus $b_{M, N}-S_{M}$ to a type- $M$ seller, if the seller accepts a bid of $b_{M, N}$.

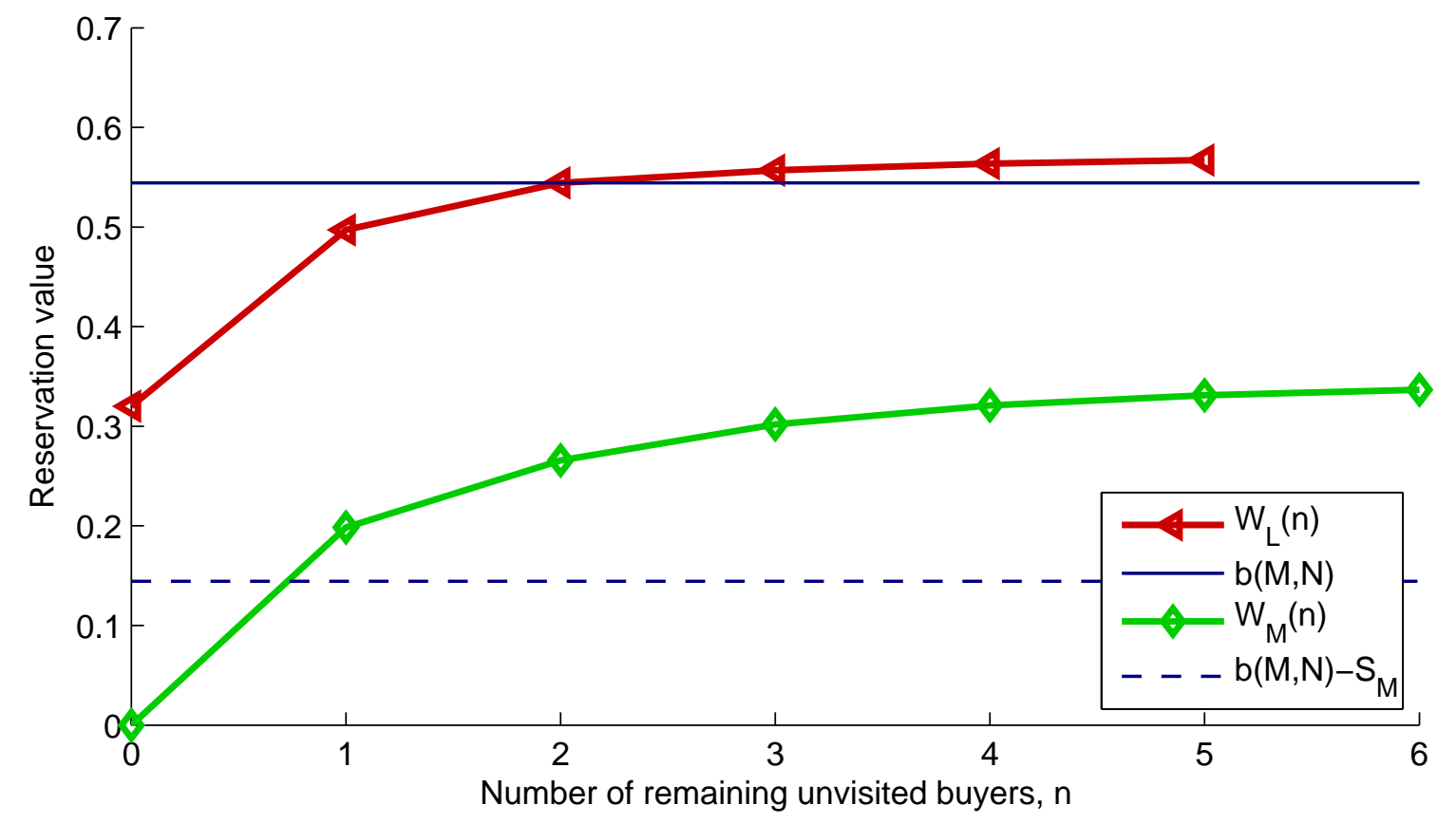

with the boundary conditions $W_{L}(0)=\delta S^{M}$ and $W_{L}^{0}(0)=0$.

Similarly, we let $W_{M}(n)$ be a type- $M$ seller's outside-option continuation value when there are $n$ buyers yet to visit. We have:

$$
\begin{aligned}
& W_{M}(n)=\delta\left(p_{H}\left(1-S_{M}\right)+\left(p_{M}+p_{L}\right) W_{M}(n-1)\right), \quad n \in\left\{J_{M}+1, J_{M}+2, \ldots, N-1\right\}, \\
& W_{M}(n)=\delta\left(p_{H}\left(1-S_{M}\right)+p_{M}\left(b_{M, N}-S_{M}\right)+p_{L} W_{M}(n-1)\right), \quad n \in\left\{1,2, \ldots, J_{M}\right\},
\end{aligned}
$$

with the boundary condition $W_{M}(0)=0$.

Given $b_{M, N}$, we have a unique solution for $\left\{W_{L}(n)\right\},\left\{W_{L}^{0}(n)\right\}$, and $\left\{W_{M}(n)\right\}$. To determine $b_{M, N}$, note that in equilibrium either $b_{M, N} \geq W_{L}\left(J_{L}\right)$ or $b_{M, N}-S_{M} \geq W_{M}\left(J_{M}\right)$ must be binding, for otherwise a type- $M$ buyer can lower his bid to $b_{M, N}-\epsilon$, for some $\epsilon>0$, without changing the equilibrium outcome along any path. Either equality can determine an equilibrium: If $b_{M, N}=W_{L}\left(J_{L}\right)$, then a type- $M$ seller endogenously chooses $J_{M}=\max \left\{n: b_{M, N}-S_{M} \geq W_{M}(n)\right\}$. If $b_{M, N}-S_{M}=W_{M}\left(J_{M}\right)$, then a type- $L$ seller endogenously chooses $J_{L}=\max \left\{n: b_{M, N} \geq W_{L}(n)\right\}$. 
Figure 6 shows one such conjectured equilibrium in a market with $N=6$ buyers, for the parameters $\delta=0.8, p_{L}=p_{M}=p_{H}=1 / 3, J_{L}=2$, and $S_{M}=0.4$. In this conjectured equilibrium, $b_{M, N}=W_{L}(2)=0.54$, and a type- $M$ seller endogenously chooses $J_{M}=0$. As intuition suggests, a seller's continuation value declines as the number of remaining unvisited buyers decreases. In this example, conditional on having met a type- $M$ buyer, a type- $L$ seller accepts a bid of $b_{M, N}$ only after having visited at least $N-2$ buyers, and a type- $M$ seller accepts a price of $b_{M, N}$ if and only if she has visited all $N$ buyers.

The conjectured strategies constitute an equilibrium subject to incentive conditions. Although I do not verify these conditions explicitly, the intuition behind them is similar to that of the repeat-contact equilibrium of Theorem $1 .^{6}$

I now consider the limiting behavior of the market when the number $N$ of buyers approaches infinity. With infinitely many potential counterparties, the seller can avoid returning to any previously visited buyer, and her strategy becomes stationary. I conjecture the following stationary separating equilibrium: A type- $\theta$ buyer bids $b_{\theta}$, whereas a type- $\theta$ seller accepts a price no lower than $A_{\theta}$, where $b_{\theta}$ and $A_{\theta}$ are given by:

\begin{tabular}{c|ccc} 
& $\theta=L$ & $\theta=M$ & $\theta=H$ \\
\hline$b_{\theta}$ & 0 & $b_{M, \infty}$ & 1 \\
$A_{\theta}$ & $b_{M, \infty}$ & 1 & 1
\end{tabular}

As before, we let $W_{\theta}$ be a type- $\theta$ seller's stationary continuation value. We have the stationary Bellman equations:

$$
\begin{aligned}
W_{L} & =\delta\left(p_{H}+p_{M} b_{M, \infty}+p_{L} W_{L}\right), \\
W_{M} & =\delta\left(p_{H}\left(1-S_{M}\right)+\left(p_{M}+p_{L}\right) W_{M}\right),
\end{aligned}
$$

with the equilibrium restriction $W_{L}=b_{M, \infty}$. Solving for $W_{L}$ and $W_{M}$, we have

$$
\begin{aligned}
W_{L} & =b_{M, \infty}=\frac{\delta p_{H}}{\delta p_{H}+1-\delta}, \\
W_{M} & =\frac{\delta p_{H}\left(1-S_{M}\right)}{\delta p_{H}+1-\delta}
\end{aligned}
$$

We can verify that $W_{M}>b_{M, \infty}-S_{M}$. Thus it is optimal for a type- $M$ seller to reject the bid $b_{M, \infty}$. With infinitely many potential counterparties, there is almost surely no repeat contact. Using the parameters $\left(S_{M}, \delta, p\right)$ shown in Figure 6, we have $b_{M, \infty}=W_{L}=0.57$, and $W_{M}=0.34$. Explicit verification of the buyers' incentive conditions is omitted.

\footnotetext{
${ }^{6}$ Admittedly, the $N$-buyer model differs slightly from the 2-buyers model. In the $N$-buyer model, a type- $L$ seller may not accept a price of $b_{M, N}$ upon the first contact. Therefore a type- $M$ buyer is uncertain of a returning seller's value. Such imperfect inference, however, may only decrease the price quote upon a repeat contact.
} 


\section{Adverse Selection with Common Value}

So far, I have analyzed a model of an opaque over-the-counter market with private values. In this section, I incorporate a common value into the model. As the second main result of this paper, I show that market opacity can exacerbate adverse selection, reduce equilibrium prices, and lead to market breakdown.

To isolate the effect of adverse selection, here I assume that there is no discounting $(\delta=1)$. I also slightly vary the time frame of the model, so that trading may happen at any time $t \in[0,1)$ and the seller's arriving time $\tau_{S}$ is uniformly distributed in $(0,1)$. The seller contacts buyers in random order, and contact is instantaneous, ${ }^{7}$ so buyers do not know the order of contact. They assign an equal unconditional probability $1 / N$ that he is the first buyer to be contacted.

The "state of the world" is either $H$ (high) or $L$ (low), with respective probabilities $p_{H}$ and $p_{L}=1-p_{H}$. In state $\theta \in\{L, H\}$, the asset pays a dividend of $V_{\theta}$ at time $t=1$. The seller knows the state $\theta$. The buyers do not observe $\theta$, but do observe independent noisy signals $\theta^{\prime} \in\{H, L\}$, where $\theta^{\prime}=\theta$ with probability $q \in(0.5,1)$. Moreover, the seller is distressed, so she values the asset at a fraction $D$ of its fundamental value, where $D \in(0,1)$ is a commonly known constant. The buyers value the asset at its fundamental value $V$. I further assume that adverse selection is sufficiently large, in that

$$
V_{L}<D V_{H}
$$

so an asset with value $V_{H}$ is never sold at a price of $V_{L}$ or lower.

I show that the combined effect of contact-order uncertainty and lack of pre-trade transparency induces a "dynamic" adverse-selection problem. Suppose that a buyer receives the high signal $H$. By Bayes' rule, his conditional expectation of the value of the asset is

$$
E\left(V \mid \theta^{\prime}=H\right)=\frac{q p_{H}}{q p_{H}+(1-q) p_{L}} V_{H}+\frac{(1-q) p_{L}}{q p_{H}+(1-q) p_{L}} V_{L}
$$

which is strictly higher than the prior, $E(V)=p_{H} V_{H}+p_{L} V_{L}$. However, conditional on being visited, a buyer reasonably suspects that the only reason he gets contacted is because (some) other buyers have observed low signals! Such adverse inference lowers conditional expectation of the asset value. That is,

$$
E\left(V \mid \theta^{\prime}=H, \text { contact, } N\right)<E\left(V \mid \theta^{\prime}=H\right) .
$$

\footnotetext{
${ }^{7}$ The instantaneous contacts can be approximated as the length of "one-period" shrink to zero.
} 
Theorem 2 (Adverse Selection in Opaque Markets). Suppose all sellers accept a (perfectly revealing) bid from a buyer who observes signal $H$. Then conditional on being contacted, a buyer who observes signal $\theta^{\prime}$ has expected fundamental value of the asset of

$$
\begin{aligned}
& E\left(V \mid \theta^{\prime}=H, \text { contact }, N\right)=\frac{\left(1-(1-q)^{N}\right) p_{H} V_{H}+\left(1-q^{N}\right) p_{L} V_{L}}{\left(1-(1-q)^{N}\right) p_{H}+\left(1-q^{N}\right) p_{L}} \\
& E\left(V \mid \theta^{\prime}=L, \text { contact }, N\right)=\frac{\left(\frac{1-q}{q}\right)\left[1-(1-q)^{N}\right] p_{H} V_{H}+\left(\frac{q}{1-q}\right)\left[1-q^{N}\right] p_{L} V_{L}}{\left(\frac{1-q}{q}\right)\left[1-(1-q)^{N}\right] p_{H}+\left(\frac{q}{1-q}\right)\left[1-q^{N}\right] p_{L}}
\end{aligned}
$$

Both $E\left(V \mid \theta^{\prime}=H\right.$, contact, $\left.N\right)$ and $E\left(V \mid \theta^{\prime}=L\right.$, contact, $\left.N\right)$ are strictly decreasing in N. Moreover, if

$$
E\left(V \mid \theta^{\prime}=H, \text { contact }, N\right)>D V_{H}>E\left(V \mid \theta^{\prime}=L, \text { contact }, N\right)
$$

then there exists a symmetric equilibrium in which:

1. A buyer who observes the signal $L$ bids $V_{L}$ and a buyer who observes the signal $H$ bids $D V_{H}$.

2. A seller searches through $N$ buyers and accepts the first bid that is at least $D V_{H}$. If no buyer bids $D V_{H}$, then a value-H seller leaves the market, whereas a value- $L$ seller accepts $V_{L}$ from any buyer with equal probabilities.

Proof. See Appendix C.

Proposition 2 (Market Breakdown). For any $q<1$, as $N \rightarrow \infty$,

$$
\begin{aligned}
& E\left(V \mid \theta^{\prime}=H, \text { contact }, N\right) \rightarrow p_{H} V_{H}+p_{L} V_{L} \\
& E\left(V \mid \theta^{\prime}=L, \text { contact }, N\right) \rightarrow \frac{(1-q)^{2} p_{H}}{(1-q)^{2} p_{H}+q^{2} p_{L}} V_{H}+\frac{q^{2} p_{L}}{(1-q)^{2} p_{H}+q^{2} p_{L}} V_{L} .
\end{aligned}
$$

That is, buyers' signals are irrelevant in the limit. Moreover, if $D V_{H}>p_{H} V_{H}+p_{L} V_{L}$, then for any $q<1$, there exists an $N^{\prime}$, such that in a market with at least $N^{\prime}$ buyers,

$$
D V_{H}>E\left(V \mid \theta^{\prime}=H, \text { contact }, N\right) \text {. }
$$

That is, the equilibrium stated in Theorem 2 does not exist. In particular, no transaction takes place at a price of $D V_{H}$ or higher.

Proof. This follows immediately from (6), (7), and (8). 
Figure 7: Expected value of the asset conditional on being contacted, as a function of the number $N$ of buyers in the market, assuming the seller chooses the order of contacts at random. Parameters: $V_{H}=1, V_{L}=0.5, D=0.8$, and $p_{H}=p_{L}=0.5$.

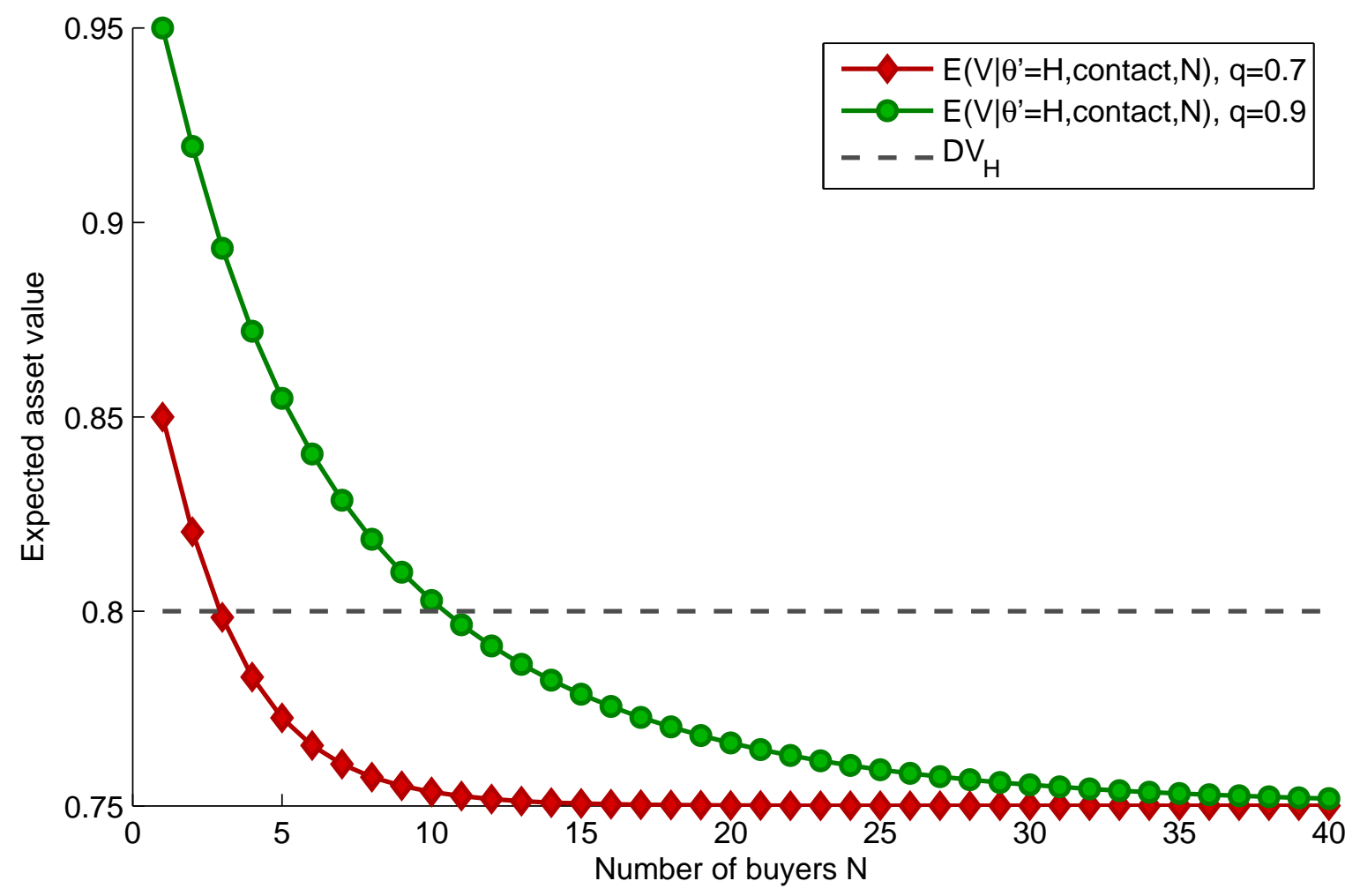

Figure 7 shows that the buyer's expected value of the asset, conditional on being contacted, decreases quickly as $N$ becomes large. A transaction occurs only if (8) holds. The buyer's expected value of the asset conditional on the signal alone is higher than the seller's value, implying a positive gain from trade. However, when $N$ is sufficiently large, adverse selection causes a market breakdown. For a relatively high precision of $q=0.7$ and a seller's discount of $D=0.8$, the market breaks down if there are more than two buyers. When $q=0.9$, the market breaks down if more than 10 buyers are present.

Key to the adverse selection effect identified in Theorem 2 are two related features of the market structure: (a) the lack of pre-trade transparency, so that the seller cannot directly identify a suitable buyer, and (b) uncertain contact order, so that when the asset is offered for sale, it is believed by the potential buyer to be difficult to sell. Welfare loss due to market breakdown is particularly striking when signals are precise and the market size is large, as shown in Figure 7. In a transparent market with observable signals or quotes, a large number of buyers promotes information aggregation and price discovery 
(by the law of large numbers). In contrast, in the opaque market considered here, a large number of buyers exacerbates adverse selection and may destroy price discovery.

Perhaps surprisingly, the market breakdown suggests that an opaque market could benefit from fragmentation, which effectively reduces the number $N$ of quote-providing intermediaries. Such a market structure - fragmented intermediation with little pretrade transparency - closely resemble the OTC markets for many fixed-income securities and derivatives. ${ }^{8}$ For example, the top 5 dealer banks account for over $95 \%$ of total banking industry notional amounts in derivatives in the U.S., according to data from the Office of the Comptroller of the Currency. ${ }^{9}$ Fragmentation may stem from dealers' specialization in particular asset classes, from long-lasting trading relationships, or from costly information acquisition. We now briefly discuss the effect of fragmentation in opaque markets.

\subsection{Concentrating adverse selection by fragmentation}

Although fragmentation may help avoid market breakdown, it does not eliminate adverse selection, but rather concentrates it. To see why, suppose that the true asset value is $V_{H}$, and that

$$
D V_{H}>E\left(V \mid \theta^{\prime}=H, \text { contact }, N\right),
$$

where the right hand side is given by (6). As shown in Proposition 2, this "consolidated" market breaks down due to adverse selection. Now consider an alternative, fragmented market in which the seller visits a "favored" group of $K$ buyers before visiting the remaining, "disfavored" group of $N-K$ buyers. (I assume that the seller can commit to such a strategy, without explicitly modeling the contracting arrangement that delivers such commitment.) Within each group, the seller chooses a random contact order. The level of fragmentation, $K$, is chosen such that

$$
E\left(V \mid \theta^{\prime}=H, \text { contact }, K\right)>D V_{H}>E\left(V \mid \theta^{\prime}=L, \text { contact }, K\right) .
$$

Thus gain from trade is realized as long as there is at least one favored buyer who receives an $H$-signal.

In the event that no buyer in the favored group receives the high signal, which happens with probability $(1-q)^{K}$, a visited type- $H$ disfavored buyer updates his "prior"

\footnotetext{
${ }^{8}$ See, for example, Bessembinder and Maxwell (2008), Green, Hollifield, and Schürhoff (2007), and ISDA (2009).

${ }^{9}$ See http://www.occ.treas.gov/ftp/release/2010-33a.pdf.
} 
belief of the state $\theta$ to be

$$
\left(p_{H}^{\prime}, p_{L}^{\prime}\right)=\left(\frac{(1-q)^{K} p_{H}}{(1-q)^{K} p_{H}+q^{K} p_{L}}, \frac{q^{K} p_{L}}{(1-q)^{K} p_{H}+q^{K} p_{L}}\right)
$$

and values the asset at

$E\left(V \mid \theta^{\prime}=H\right.$, contact, $\left.N-K ; K \times L\right)=\frac{\left(1-(1-q)^{N-K}\right)(1-q)^{K} p_{H} V_{H}+\left(1-q^{N-K}\right) q^{K} p_{L} V_{L}}{\left(1-(1-q)^{N-K}\right)(1-q)^{K} p_{H}+\left(1-q^{N-K}\right) q^{K} p_{L}}$.

The above expression follows from rewriting (6) using the new "prior" beliefs $\left(p_{H}^{\prime}, p_{L}^{\prime}\right)$. We can show that, $E\left(V \mid \theta^{\prime}=H\right.$, contact, $\left.N-K ; K \times L\right)$ decreases in $K{ }^{10}$ Thus

$$
E\left(V \mid \theta^{\prime}=H, \text { contact, } N-K ; K \times L\right)<E\left(V \mid \theta^{\prime}=H \text {, contact, } N\right)<D V_{H} .
$$

That is, disfavored buyers assign an even lower value for the asset than in the consolidated market, and never purchase the asset. Fragmentation concentrates adverse selection to the disfavored group of buyers.

Interestingly, this fragmented structure of an opaque market is analogous to the structure of trading in the markets for mortgage-backed securities (MBS), asset-backed securities (ABS), and collateralized debt obligations (CDOs). Both market structures involve creating liquidity by "pooling and tranching" (DeMarzo (2005)). In the fragmented market considered here, the seller "tranches" the pool of counterparties, just as a CDO structure tranches the pool of underlying assets. Liquidity is created in the favored group of buyers, just like the liquidity created for the senior tranche of a CDO. Adverse selection, however, is not eliminated, but transferred and concentrated to other parts of the market.

\footnotetext{
${ }^{10}$ We can show that

$\frac{(1-q)^{K+1}-(1-q)^{N}}{q^{K+1}-q^{N}}-\frac{(1-q)^{K}-(1-q)^{N}}{q^{K}-q^{N}}=\frac{(1-q)^{K} q^{K}}{\left(q^{K+1}-q^{N}\right)\left(q^{K}-q^{N}\right)}\left[q^{N-K+1}-(1-q)^{N-K+1}-(q-(1-q))\right] \leq 0$.
}

The last inequality follows from the fact that $q^{M}-(1-q)^{M}$ decreases in $M$ for positive integer $M$ :

$$
q^{M+1}-(1-q)^{M+1}-\left(q^{M}-(1-q)^{M}\right)=-q^{M}(1-q)+(1-q)^{M} q \leq 0 .
$$




\section{Conclusion}

This paper offers a model of price behavior in opaque over-the-counter markets. Quote seekers search for an attractive price by contacting quote providers in sequence, and possibly repeatedly. I show that a repeat contact reveals a quote seeker's reduced outside options and worsens the quote from the revisited counterparty.

I also show that the combined effects of market opacity and contact-order uncertainty can create adverse selection that is sufficiently severe to cause a market breakdown. When the fundamental value of the asset is of concern, a quote provider is concerned not only about the private information of the quote seeker, but also about signals received by other quote providers. Quote providers infer that an asset offered for sale is probably difficult to sell, and thus quote low prices, even when they all observe relatively precise signals indicating that the value of the asset is high. Market fragmentation may help avoid market breakdown, but only at the cost of concentrating adverse selection in other parts of the market. 


\section{Appendices}

\section{A Proof of Theorem 1}

We observe that a type- $H$ buyer's bid is no greater than 1 . To see why, suppose for contradiction that along some equilibrium path, a type- $H$ buyer bids some price $b_{H}>1$. Then the surplus to the seller is at least $b_{H}-1>0$. Because the cost of delay to the seller is at least $(1-\delta)\left(b_{H}-1\right)>0$, a type- $H$ buyer can profitably deviate by quoting $b_{H}-\epsilon$, for any positive $\epsilon<(1-\delta)\left(b_{H}-1\right)$, a contradiction of optimality. It follows that the highest bid in the market is at most 1 , which is equal to the highest possible value, $S_{H}$, of a seller. Thus a type- $H$ seller accepts a bid of 1 as soon as it is received. ${ }^{11}$

I prove Theorem 1 in three steps. In the first step, I show that a type- $M$ buyer bids $S_{M}$ upon the second and any subsequent contact. To see this, suppose that Buyer $i$ is of type $M$. According to the equilibrium strategy, a type- $M$ seller rejects Buyer $i$ 's first bid $b_{M}$, and contacts Buyer $-i$. Buyer $i$ does not observe the bid by Buyer $-i$, but he infers it to be 0 upon the second contact by the seller. Buyer $i$ also infers that the returning seller is of type $M$, by separation. Now the type- $M$ buyer has monopoly power over the type- $M$ seller and bids $S_{M}$. The seller, knowing the price will never improve, accepts it. The following proposition summarizes this result.

Proposition 3 (Second Bid and Limited Delay). Suppose that in a symmetric, fullyrevealing separating equilibrium the seller switches buyers or exits the market after each contact. Then a buyer of type-M bids $S_{M}$ upon the second contact and any subsequent contact, and the seller accepts the bid of $S_{M}$.

In the second step, I show that the first bid of a type- $M$ buyer equals a type- $L$ seller's outside option.

Proposition 4 (First Bid). Suppose that in a symmetric, fully-revealing separating equilibrium the seller switches buyers or exits the market after each contact. Then:

(a). The first bid of a type-M Buyer $i, b_{M, 1}^{i}$, is a $F_{0}^{i}$-measurable constant.

(b). The first bid $b_{M}$, given by (1), is optimal for a type-M buyer and satisfies

$$
S_{M}<b_{M}<B_{M}
$$

\footnotetext{
${ }^{11}$ By Diamond (1971) and Stiglitz (1979), if a seller's reservation value is known and cost of search is strictly positive, then sellers quote the monopoly price.
} 
under the two conditions:

$$
\begin{aligned}
S_{M}<\frac{\delta p_{H}}{1-\delta p_{M}-\delta^{2} p_{L}} \\
S_{M}>\frac{\delta p_{H}}{R\left(1-\delta p_{M}\right)-\delta^{2} p_{L}} .
\end{aligned}
$$

When (1),(11), and (12) hold, a type-M seller accepts a bid of $b_{M}$ from the second buyer.

Proof. (a) In a separating equilibrium, the type- $M$ Buyer $i$ sets his first bid such that in the event he is the first buyer contacted $\left(\left\{\tau_{i}=\tau_{S}+1\right\}\right)$, a type- $L$ seller accepts his first bid. Given $\left\{\tau_{i}=\tau_{S}+1\right\}$, Buyer $i$ 's conditional probability distribution of $\left(B^{(-i)}, S\right)$ is the prior. Then the first bid $b_{M, 1}$ is an $F_{0}^{i}$-measurable constant.

(b) Suppose $b_{M}>S_{M}$. The incentive compatibility of a type- $L$ seller implies that

$$
b_{M} \geq \delta\left(p_{L} \delta S_{M}+p_{M} b_{M}+p_{H} \cdot 1\right) .
$$

In equilibrium, (IC-L) holds with equality, and (1) follows. It is easy to verify that (11) is equivalent to $b_{M}>S_{M}$. The buyer's rationality condition $B_{M}=R S_{M}>b_{M}$ reduces to (12). The type- $M$ seller accepts a bid of $b_{M}$ from the second buyer, because it gives the seller a higher surplus than the first buyer's reduced bid of $S_{M}$.

So far in my proof of Theorem 1, I have taken it as given that, in equilibrium, a seller chooses to switch buyers or to exit the market after each contact. Now, I endogenize the seller's choice.

Proposition 5 (Switching Buyers). Suppose (1),(11), and (12) hold. In a separating equilibrium, a seller contacts the second buyer immediately after rejecting the first buyer.

Proof. Suppose that the seller is of type $M$. In a separating equilibrium, this seller rejects the first bids from buyers of type $L$ and type $M$. Clearly, the seller does not contact a type- $L$ buyer for a second time, because his bid is always 0 . Now suppose that the first buyer is of type $M$. If the seller contacts the second buyer right after rejecting the first, then the seller's expected surplus is $p_{M}\left(b_{M}-S_{M}\right)+p_{H}\left(1-S_{M}\right)$. If, instead, the seller contacts the first buyer again before contacting the second, then the first buyer never quotes more than $\bar{b}_{M}$, where $\bar{b}_{M}$ is a type- $M$ seller's outside option, ${ }^{12}$ given by (3). Therefore, the seller's surplus from contacting the second buyer is strictly higher

\footnotetext{
${ }^{12}$ If the seller contacts the first buyer again before contacting the second, then first buyer's second bid must also be at most $b_{M} / \delta$, as otherwise a type- $L$ seller may imitate the type- $M$ seller. We do not have to explicitly calculate this restriction, because it may only decrease the first buyer's second bid.
} 
than the surplus from contacting the first. Waiting for a period or more only discounts gain from trade and is not optimal. The arguments for a type- $H$ or type- $L$ sellers are similar.

Proof of equilibrium belief and uniqueness in Theorem 1: The equilibrium belief 3(i) of Theorem 1 follows from perfect revelation. The equilibrium belief $3(i i)$ follows because a type- $M$ seller is the only one who makes a repeat contact in equilibrium. For belief $3($ iii $)$, note that a buyer is contacted either because he is the first (with probability 0.5 ) or he is the second but the other buyer does not transact (with probability $0.5\left(p_{L}+\right.$ $\left.\left.p_{M}\left(p_{M}+p_{H}\right)\right)\right)$. By Bayes' rule,

$$
\begin{aligned}
P\left(\tau_{S}=\tau_{i}-1 \mid \tau_{i}=t\right) & =\frac{P\left(\tau_{S}=t-1\right) \cdot 0.5}{P\left(\tau_{S}=t-1\right) \cdot 0.5+P\left(\tau_{S}=t-2\right) \cdot 0.5\left(p_{L}+p_{M}\left(p_{M}+p_{H}\right)\right)} \\
& =\frac{\rho}{\rho+p_{L}+p_{M}\left(p_{M}+p_{H}\right)} .
\end{aligned}
$$

Together, Propositions $3-5$ as well as the previous paragraph verify that the strategies stated in Theorem 1 constitute an equilibrium, subject to (11), (12), and other equilibrium incentive-compatibility conditions, provided in Appendix A.1. These conditions define the open set of parameters described in the statement of Theorem 1. Appendix A.1 shows that such open set of parameters is nonempty.

The existence of a repeat-contact event in the equilibrium of Theorem 1 is also robust to the off-equilibrium refinement associated with the Intuitive Criterion (Cho and Kreps (1987)). ${ }^{13}$ Finally, uniqueness follows from the uniqueness of the first bid $b_{M}$.

\section{A.1 Incentive conditions of the repeat-contact equilibrium}

In this appendix I derive the incentive conditions for the existence of the repeat-contact equilibrium of Theorem 1. From Theorem 1, conditional on being contacted for the first time at $t \geq 2$, the probability that a buyer is the first ever contacted by the seller is $\alpha$, given by (2).

I now characterize the necessary and sufficient conditions under which a type- $M$ buyer bids $b_{M}$, given by (1), upon the first contact.

\footnotetext{
${ }^{13}$ Because both type- $L$ and type- $H$ buyers have dominant strategies (a type- $L$ buyer bids 0 and a type- $H$ buyer bids 1$)$, they will not deviate by quoting a price in $\left(0, B_{M}\right)$, regardless of the seller's beliefs. A type- $M$ buyer, however, may profitably deviate and make such a bid. Upon receiving a bid in $\left(0, B_{M}\right)$, the unique belief of the seller that is consistent with the Intuitive Criterion is that the buyer is of type $M$. All types of buyers have a dominant strategy of not bidding in $\left(B_{M}, 1\right)$, so the Intuitive Criterion does not apply to such deviations. The off-equilibrium belief for deviations in $\left(B_{M}, 1\right)$ is thus not generally unique.
} 
Now consider the incentive compatibility of a type- $M$ Buyer $i$ to bid $b_{M}$ upon the first contact. There are three ways he buys the asset. First, with probability $\alpha p_{L}$, Buyer $i$ is the first contacted and the seller is of type $L$. In this case Buyer $i$ buys the asset at $b_{M}$, making expected profit $\alpha\left(B_{M}-b_{M}\right) p_{L}$. Second, with probability $\alpha p_{M}$, Buyer $i$ is the first contacted and the seller of type $M$. In this case the seller rejects a bid of $b_{M}$ and contacts the other buyer. But if the other buyer bids a low price (with probability $p_{L}$ ), then the type- $M$ seller returns and accepts the price $S_{M}$. The buyer's expected profit in this case is $\alpha\left(B_{M}-S_{M}\right) p_{M} p_{L}$. Third, with probability $1-\alpha$, Buyer $i$ is the second contacted. Trading occurs at $b_{M}$ if the seller is either of type $M$ (who rejected type- $M$ and type- $L$ buyers) or of type $L$ (who rejected a type- $L$ buyer). In this case expected profit is $(1-\alpha)\left(B_{M}-b_{M}\right)\left[p_{M}\left(p_{L}+p_{M}\right)+p_{L} p_{L}\right]$. Overall, conditional on being contacted, a type- $M$ buyer's expected profit from quoting $b_{M}$ upon the first contact is

$\Pi\left(b_{M}\right)=\alpha\left(B_{M}-b_{M}\right) p_{L}+\alpha \delta^{2}\left(B_{M}-S_{M}\right) p_{M} p_{L}+(1-\alpha)\left(B_{M}-b_{M}\right)\left[p_{M}\left(p_{L}+p_{M}\right)+p_{L} p_{L}\right]$.

Now we consider possible deviations. The first possible deviation is to raise his bid such that a type- $M$ seller accepts it, even if Buyer $i$ is the first contacted. The lowest such bid, $\bar{b}_{M}$, is given by (3). Similar to above, we can calculate the buyer's expected profit of quoting $\bar{b}_{M}$,

$$
\Pi\left(\bar{b}_{M}\right)=\alpha\left(B_{M}-\bar{b}_{M}\right)\left(p_{L}+p_{M}\right)+(1-\alpha)\left(B_{M}-\bar{b}_{M}\right)\left[p_{M}\left(p_{L}+p_{M}\right)+p_{L} p_{L}\right] .
$$

Incentive compatibility thus requires

$$
\Pi\left(\bar{b}_{M}\right)<\Pi\left(b_{M}\right)
$$

Buyer $i$ 's second possible deviation is to lower the first bid such that, if $\tau_{i}<\tau_{-i}$, then both type- $L$ and type- $M$ sellers reject this first bid and contact the other buyer. Along this deviated path, if the seller returns to Buyer $i$ after two periods, Buyer $i$ can no longer infer the precise type of the seller. The only information he knows, at time $\tau_{i}+2$, is that the other buyer is not the of type $H$. Appendix A.2 establishes that the quoted price in this case is either 0 or $S_{M}$. Thus along this deviation path, Buyer $i$ 's strategy consists of a pair of (time-invariant) bids for the first and the second contact, respectively. If the first bid is $S_{M}$, then a type- $M$ seller accepts it if $\tau_{i}>\tau_{-i}$. (There is 
no need to bid more than $S_{M}$.) The buyer's expected surpluses are

$$
\begin{aligned}
\Pi\left(S_{M}, 0\right) & =(1-\alpha)\left(B_{M}-S_{M}\right)\left[p_{M} p_{M}+p_{L}\left(p_{L}+p_{M}\right)\right]+\alpha \delta^{2} B_{M} p_{L} p_{L}, \\
\Pi\left(S_{M}, S_{M}\right) & =(1-\alpha)\left(B_{M}-S_{M}\right)\left[p_{M} p_{M}+p_{L}\left(p_{L}+p_{M}\right)\right]+\alpha \delta^{2}\left(B_{M}-S_{M}\right) p_{L}\left(p_{L}+p_{M}\right) .
\end{aligned}
$$

If the first bid is less than $S_{M}$, then the buyer is to play like a monopolist from the very start, because along this deviation path the buyer makes any purchase if and only if the other buyer is of type $L$. If $B_{M} p_{L} \geq\left(B_{M}-S_{M}\right)\left(p_{L}+p_{M}\right)$, monopoly outcome is to always bid (slightly more than) 0 (Appendix A.2), thus

$$
\Pi(0,0)=\alpha \delta^{2} B_{M} p_{L} p_{L}+(1-\alpha) B_{M} p_{L} p_{L}
$$

If $B_{M} p_{L}<\left(B_{M}-S_{M}\right)\left(p_{L}+p_{M}\right)$, then the monopoly outcome is to bid $S_{M}$, implying it cannot be optimal to bid anything less than $S_{M}$ on the first contact.

Hence incentive compatibility of "downward" deviation requires

$$
\Pi\left(b_{M}\right)>\max \left(\Pi(0,0), \Pi\left(S_{M}, 0\right), \Pi\left(S_{M}, S_{M}\right)\right) .
$$

Taking the two cases together, the incentive-compatibility conditions for a type- $M$ buyer are (13) and (14).

I now characterize the necessary and sufficient conditions under which a type- $H$ buyer bids 1 upon the first contact. As before, suppose the type- $H$ buyer in questions is Buyer $i$. Apart from his equilibrium bid of 1 , the possible bids of the buyer are exactly the same as those of a type- $M$ buyer: $0, S_{M}, b_{M}$, and $\bar{b}_{M}$. Denote by $\Gamma(b)$ the expected surplus of a type- $H$ buyer for bidding $b$ when $\tau_{i}>1$, we have:

$$
\begin{aligned}
\Gamma(1) & =B_{H}-1, \\
\Gamma\left(\bar{b}_{M}\right) & =\alpha\left(B_{H}-\bar{b}_{M}\right)\left(p_{L}+p_{M}\right)+(1-\alpha)\left(B_{H}-\bar{b}_{M}\right)\left[p_{M}\left(p_{L}+p_{M}\right)+p_{L} p_{L}\right], \\
\Gamma\left(b_{M}\right) & =\alpha\left(B_{H}-b_{M}\right) p_{L}+\alpha \delta^{2}\left(B_{H}-S_{M}\right) p_{M} p_{L}+(1-\alpha)\left(B_{H}-b_{M}\right)\left[p_{M}\left(p_{L}+p_{M}\right)+p_{L} p_{L}\right], \\
\Gamma\left(S_{M}, 0\right) & =(1-\alpha)\left(B_{H}-S_{M}\right)\left[p_{M} p_{M}+p_{L}\left(p_{L}+p_{M}\right)\right]+\alpha \delta^{2} B_{H} p_{L} p_{L}, \\
\Gamma\left(S_{M}, S_{M}\right) & =(1-\alpha)\left(B_{H}-S_{M}\right)\left[p_{M} p_{M}+p_{L}\left(p_{L}+p_{M}\right)\right]+\alpha \delta^{2}\left(B_{H}-S_{M}\right) p_{L}\left(p_{L}+p_{M}\right), \\
\Gamma(0,0) & =\alpha \delta^{2} B_{H} p_{L} p_{L}+(1-\alpha) B_{H} p_{L} p_{L} .
\end{aligned}
$$

The incentive-compatibility conditions for the type- $H$ buyer are:

$$
\Gamma(1)>\max \left(\Gamma\left(\bar{b}_{M}\right), \Gamma\left(b_{M}\right), \Gamma\left(S_{M}, 0\right), \Gamma\left(S_{M}, S_{M}\right), \Gamma(0,0)\right)
$$


Combined, (11), (12), (13), (14), and (15) define the open set of parameters $\left(B_{M}, R, \delta, p, \rho\right)$, for which the repeat-contact equilibrium exists, as stated in Theorem 1 . Figure 5 in the text illustrates that for some parameter value $\left(S_{M}, R, \delta, p, \rho\right)$ the repeat-contact equilibrium of Theorem 1 exists. The non-emptiness of the open set follows from the continuity of the incentive conditions.

\section{A.2 Monopoly outcome}

In this appendix I solve the model of Section 2 with only one buyer, who is of type $M$. His relevant trading counterparties are type- $L$ and type- $M$ sellers. Since there is no outside options, the buyer screens a type- $L$ seller from a type- $M$ seller by improving his bids over time, as in standard bargaining literature. Suppose the buyer wants to conclude trade in $n+1$ periods, then in the last period he bids $S_{M}$ and sells to a type- $M$ buyer. Incentive compatibility of a type- $L$ seller then implies that the buyer's first bid is no lower than $\delta^{n} S_{M}$, that his second bid is no lower than $\delta^{n-1} S_{M}$, and so on. Over $n+1$ periods the buyer slowly raises his bid: $\delta^{n} S_{M}, \delta^{n-1} S_{M}, \ldots, \delta S_{M}, S_{M}$. A type- $M$ seller trades in period $n+1$, and a type- $L$ seller trades in period 1 (by tie-breaking rule). Expected profit of the buyer is then

$$
p_{L}\left(B_{M}-\delta^{n} S_{M}\right)+p_{M} \delta^{n}\left(B_{M}-S_{M}\right)=p_{L} B_{M}+\delta^{n}\left(p_{M} B_{M}-\left(p_{L}+p_{M}\right) S_{M}\right),
$$

which is monotone in $n$. When $p_{M} B_{M}>\left(p_{L}+p_{M}\right) S_{M}$, the buyer bids $S_{M}$ in the first period $(n=0)$, and both types of sellers accept. When $p_{M} B_{M} \leq\left(p_{L}+p_{M}\right) S_{M}$, the buyer always bids $0(n \rightarrow \infty)$, and only a type- $L$ seller accepts, assuming the seller is able to commit not to raise price later. Thus the dynamic, infinite-horizon trading game ends upon the first contact, an outcome that would have occurred in a one-period, monopolist setting. I refer to it as the monopoly outcome.

\section{B Existence of the First-Mover Equilibrium}

In this appendix I calculate the incentive conditions for the first-mover equilibrium stated in Section 4.1, in which the first buyer knows the order of contact (but the second buyer does not). The first buyer's bid is $\bar{b}_{M}$, given by (3).

Let $\Pi_{1}(\cdot)$ a type- $M$ buyer's expected surplus, conditional on his knowing that he is 
the first. We have

$$
\begin{aligned}
\Pi_{1}\left(\bar{b}_{M}\right) & =\left(B_{M}-\bar{b}_{M}\right)\left(p_{L}+p_{M}\right), \\
\Pi_{1}\left(b_{M}\right) & =\left(B_{M}-b_{M}\right) p_{L}+\delta^{2}\left(B_{M}-S_{M}\right) p_{M} p_{L}, \\
\Pi_{1}(b, 0) & =\delta^{2} B_{M} p_{L} p_{L} \equiv \Pi_{1}^{L}(0), \quad \forall b<b_{M}, \\
\Pi_{1}\left(b, S_{M}\right) & =\delta^{2}\left(B_{M}-S_{M}\right) p_{L}\left(p_{L}+p_{M}\right) \equiv \Pi_{1}^{L}\left(S_{M}\right), \quad \forall b<b_{M} .
\end{aligned}
$$

Similarly, let $\Gamma_{1}(b)$ be a type- $H$ buyer's expected surplus, conditional on his knowing that he is the first. We have:

$$
\begin{aligned}
\Gamma_{1}(1) & =B_{H}-1, \\
\Gamma_{1}\left(\bar{b}_{M}\right) & =\left(B_{H}-\bar{b}_{M}\right)\left(p_{L}+p_{M}\right), \\
\Gamma_{1}\left(b_{M}\right) & =\left(B_{H}-b_{M}\right) p_{L}+\delta^{2}\left(B_{H}-S_{M}\right) p_{M} p_{L}, \\
\Gamma_{1}(b, 0) & =\delta^{2} B_{H} p_{L} p_{L} \equiv \Gamma_{1}^{L}(0), \quad \forall b<b_{M}, \\
\Gamma_{1}\left(b, S_{M}\right) & =\delta^{2}\left(B_{H}-S_{M}\right) p_{L}\left(p_{L}+p_{M}\right) \equiv \Gamma_{1}^{L}\left(S_{M}\right), \quad \forall b<b_{M},
\end{aligned}
$$

Then incentive compatibility implies

$$
\begin{aligned}
\Pi_{1}\left(\bar{b}_{M}\right) & >\max \left(\Pi_{1}\left(b_{M}\right), \Pi_{1}^{L}(0), \Pi_{1}^{L}\left(S_{M}\right)\right), \\
\Gamma_{1}(1) & >\max \left(\Gamma_{1}\left(\bar{b}_{M}\right), \Gamma_{1}\left(b_{M}\right), \Gamma_{1}^{L}(0), \Gamma_{1}^{L}\left(S_{M}\right)\right) .
\end{aligned}
$$

The first-mover equilibrium thus exists when (16) and (17) hold.

\section{Proof of Theorem 2}

Suppose that a buyer who observes signal $\theta$ bids $D V_{\theta}$. I refer to a buyer who receives a signal of $H$ as a type- $H$ buyer. Because $D V_{H}$ is the highest price in the market, all sellers accept this price. When visited by the seller, a buyer of type $H$ assigns conditional probability $P(k \mid H$, contact $)$ that he is the $k^{\text {th }}$ buyer contacted by the seller. Because no sale has occurred so far, all $(k-1)$ previously visited buyers must have all observed signal L. By Bayes' rule,

$$
\begin{aligned}
P(k \mid H, \text { contact }) & =\frac{P(H, L \times(k-1))}{\sum_{k=1}^{N} P(H, L \times(k-1))} \\
& =\frac{p_{H} q(1-q)^{k-1}+p_{L} q^{k-1}(1-q)}{\sum_{j=1}^{N} p_{H} q(1-q)^{j-1}+p_{L} q^{j-1}(1-q)} .
\end{aligned}
$$


In addition, conditional on one $H$-signal and $(k-1) L$-signals, the expected value of the asset is

$$
E(V \mid H, L \times(k-1))=\frac{q(1-q)^{k-1} p_{H} V_{H}+(1-q) q^{k-1} p_{L} V_{L}}{q(1-q)^{k-1} p_{H}+(1-q) q^{k-1} p_{L}} .
$$

Then the expectation

$$
\sum_{k=1}^{N} E(V \mid H, L \times(k-1)) P(k \mid H, \text { contact })
$$

is equal to the expression of $E\left(V \mid \theta^{\prime}=H\right.$, contact, $\left.N\right)$ given in Theorem 2. Further, $E\left(V \mid \theta^{\prime}=H\right.$, contact, $\left.N\right)$ decreases in $N$ because the fraction $\left(1-(1-q)^{N}\right) /\left(1-q^{N}\right)$ decreases in $N$ :

$$
\frac{1-(1-q)^{N+1}}{1-q^{N+1}}-\frac{1-(1-q)^{N}}{1-q^{N}}=\frac{(1-q)^{N} q-q^{N}(1-q)-(1-q)^{N} q^{N}(2 q-1)}{\left(1-q^{N+1}\right)\left(1-q^{N}\right)}<0 .
$$

Transaction occurs if and only if the type- $H$ buyer's expected value, $E\left(V \mid \theta^{\prime}=H\right.$, contact, $\left.N\right)$, is higher than a type- $H$ seller's value, $D V_{H}$. The calculation of $E\left(V \mid \theta^{\prime}=L\right.$, contact, $\left.N\right)$ is similar.

It remains to show that buyers do not deviate to other quotes. Clearly, given that the highest quote in the market is $D V_{H}$ and that quote is accepted immediately, no buyers quote a higher price. Also, given that the lowest bid in the market is $V_{L}$, no buyers quote a lower price. If a type- $H$ buyer deviates to any lower quote, then he buys the asset only if the asset is worth $V_{L}$, in which case he makes zero profit at most. So a type- $H$ buyer does not deviate. Similarly, a type- $L$ buyer does not deviate to the high bid of $D V_{H}$, as otherwise he would make a loss. This completes the proof. 


\section{References}

Ausubel, L. M., P. Cramton, and R. J. Deneckere, 2002, "Bargaining with Incomplete Information," Handbook of Game Theory, Volumn 3, Edited by R.J. Aumann and S. Hart.

Barclay, M. J., T. Hendershott, and K. Kotz, 2006, "Automation versus Intermediation: Evidence from Treasuries Going Off the Run," Journal of Finance, 61(5), 2395-2414.

Bessembinder, H., and W. Maxwell, 2008, "Transparency and the Corporate Bond Market," Journal of Economic Perspectives, 22(2), 217-234.

Biais, B., 1993, "Price Formation and Equilibrium Liquidity in Fragmented and Centralized Markets," Journal of Finance, 48(1), 157-185.

Chatterjee, K., and C. C. Lee, 1998, "Bargaining and Search with Incomplete Information about Outside Options," Games and Economic Behavior, 22, 203-237.

Cheng, P., Z. Lin, and Y. Liu, 2008, "A Model of Time-on-Market and Real Estate Price Under Sequential Search with Recall," Real Estate Economics, 36(4), 813-843.

Cho, I.-K., and D. M. Kreps, 1987, "Signaling Games and Stable Equilibria," Quarterly Journal of Economics, 102(2), 179-221.

de Fraja, G., and A. Muthoo, 2000, "Equilibrium Partners Switching in a Bargaining Model with Asymmetric Information," International Economic Review, 41(4), 849869.

de Frutos, M. A., and C. Manzano, 2002, "Risk Aversion, Transparency, and Market Performance," Journal of Finance, 57(2), 959-984.

DeMarzo, P., 2005, "The Pooling and Tranching of Securities: A Model of Informed Intermediation," Review of Financial Studies, 18(1), 1-35.

Diamond, P., 1971, "A Model of Price Adjustment," Journal of Economic Theory, 3, $156-168$.

Duffie, D., N. Gârleanu, and L. H. Pedersen, 2005, "Over-the-Counter Markets," Econometrica, 73(6), 1815-1847.

— , 2007, "Valuation in Over-the-Counter Markets," Review of Financial Studies, 20(5), 1866-1900. 
Duffie, D., S. Malamud, and G. Manso, 2010, "Information Percolation in Segmented Markets," Working Paper, Stanford University.

Froot, K., 2008, "What Went Wrong and How Can We Fix It? Lessons from Investor Behaviour," 2008 Research Journal, State Street.

Fuchs, W., and A. Skrzypazc, 2008, "Bargaining with Arrival of New Traders," American Economic Review, Forthcoming.

Gantner, A., 2008, "Bargaining, search, and outside options," Games and Economic Behavior, 62, 417-435.

Glosten, L. R., and P. R. Milgrom, 1985, "Bid, Ask and Transaction Prices in a Specialist Market with Heterogenously Informed Traders," Journal of Financial Economics, 14, $71-100$.

Green, R., 2007, "Presidential Address: Issuers, Underwriter Syndicates and Aftermarket Transparency," Journal of Finance, 62(4), 1529-1549.

Green, R., B. Hollifield, and N. Schürhoff, 2007, "Dealer intermediation and price behavior in the aftermarket for new bond issues," Journal of Financial Economics, 86, 643-682.

Grossman, S., 1976, "On the Efficiency of Competitive Stock Markets Where Trades Have Diverse Information," Journal of Finance, 31(2), 573-585.

ISDA, 2009, "Transparency and over-the-counter derivatives: The role of transaction transparency," ISDA Research Notes.

Kyle, A. S., 1985, "Continuous Auctions and Insider Trading," Econometrica, 53(6), $1315-1335$.

Milgrom, P., and N. Stokey, 1982, "Information, Trade and Common Knowledge," Journal of Economic Theory, 26, 17-27.

Muthoo, A., 1995, "On the Strategic Role of Outside Options in Bilateral Bargaining," Operations Research, 43(2), 292-297.

Quan, D. C., and J. M. Quigley, 1991, "Price Formation and the Appraisal Function in Real Estate Markets," Journal of Real Estate Finance and Economics, 4, 127-146.

SIFMA, 2009, "4th Annual European Fixed Income e-Trading Survey," SIFMA Papers and Surveys. 
Stiglitz, J., 1979, "Equilibrium in Product Markets with Imperfect Information," American Economic Review, 69(2), 339-345.

Vayanos, D., and T. Wang, 2007, "Search and endogenous concentration of liquidity in asset markets," Journal of Economic Theory, 136(1), 66 - 104.

Vayanos, D., and P.-O. Weill, 2008, "A Search-Based Theory of the On-the-Run Phenomenon," Journal of Finance, 63(3), 1361-1398.

Yavas, A., 1992, "A Simple Search and Bargaining Model of Real Estate Markets," Journal of the American Real Estate and Urban Economics Association, 20(4), 533548.

Yin, X., 2005, "A Comparison of Centralized and Fragmented Markets with Costly Search," Journal of Finance, 60(3), 1567-1590.

Yinger, J., 1981, "A Search Model of Real Estate Broker Behavior," American Economic Review, 71(4), 591-605. 